\title{
EMPLEO DE ADOBES COMO MATERIAL CONSTRUCTIVO DURANTE EL PERIODO FORMATIVO E INTERMEDIO TEMPRANO EN CHURUCANA, AYACUCHO"
}

\author{
LIC. YURI I. CAVERO PALOMINO \\ UniVERSIDAd NACIONAL MAYOR DE SAN MARCos \\ yuricavero@yahoo.es \\ LIC. JHON R. HUAMANÍ DÍAZ \\ Universidad NACIONAL DE SAN CRISTÓBAL DE HUAMANGA \\ jhonhuamani@hotmail.com
}

\section{RESUMEN:}

En el presente artículo describimos los materiales arqueológicos recuperados en el sitio arqueológico de Churucana durante la ejecución del Monitoreo arqueológico de la obra “Ampliación y mejoramiento del sistema de agua potable y saneamiento en la zona rural del distrito de Quinua, provincia de Huamanga-Ayacucho. Sector "A": Muruncancha, Vista Alegre, Churucana, Huacahurara y Pampachacra". Durante el desarrollo de dichos trabajos, se hallaron secciones de muros de adobes asociados a pisos, restos de pinturas y fragmentos de cerámicas pertenecientes al Periodo Formativo. Estas estructuras arquitectónicas luego fueron reutilizadas durante los Desarrollos Regionales (Huarpa) y el Imperio Wari (Horizonte Medio).

Palabras Clave: Monitoreo Arqueológico, cerro Churucana, muros de adobes, Periodo Formativo, Huarpa. Wari.

\begin{abstract}
:
In this article we describe the archaeological materials recovered at the archaeological site of Churucana during execution of the archeological monitoring of the work "Expansion and improvement of the drinking water and sanitation in the rural district of Quinua, province of Huamanga-Ayacucho. Sector "A": Muruncancha, Vista Alegre, Churucana, Huacahurara and Pampachacra ". During the course of this work, sections of walls of adobe floors associated with remains of paintings and ceramic fragments belonging to the Formative Period were found. These architectural structures were then reused for Regional Development (Huarpa) and the Wari Empire (Middle Horizon).
\end{abstract}

KeYworDS: Archaeological monitoring, closed Churucana, adobe walls, Formative Period, Huarpa. Wari. 


\section{INTRODUCCIÓN}

El cerro Churucana es una pequeña colina con evidencias de una ocupación prehispánica a partir del Horizonte Temprano o Periodo Formativo. Se ubica hacia el extremo noreste del complejo arqueológico de Wari, y como muchos de los asentamientos prehispánicos ubicados en el valle de Ayacucho a primera vista parece tratarse de una colina sin evidencias arqueológicas. Sin embargo, en la superficie de los campos de cultivos se distinguen algunos fragmentos de cerámica y artefactos líticos ${ }^{1}$.

Fue durante la fase de reapertura de las zanjas para sustituir las tuberías de PVC que conduce el agua potable a las comunidades campesinas de Pampachacra, Churucana, Vista Alegre y Huacaurara, donde ubicamos la presencia de importantes evidencias arqueológicas focalizadas en 3 puntos de los perfiles, destacando el hallazgo en dos sectores de estructuras arquitectónicas edificadas con adobes y con restos de pinturas, los cuales, corresponden al Horizonte Temprano o Periodo Formativo y luego fueron reutilizados durante la época de los Desarrollos Regionales o Período Intermedio Temprano. Asimismo en otro sector se encontró tumbas tipo cistas y material arqueológico variado correspondiente a los Desarrollos Regionales y a la época del Imperio Wari. Las evidencias halladas durante el desarrollo del Monitoreo Arqueológico son descritos en el presente artículo.

\section{El SITIO ARQUEOLóGICO DE CHURUCANA.}

Churucana es una pequeña colina de baja altitud, que se encuentra a 3,020 msnm y forma parte del flanco noreste del valle de Ayacucho y hacia el lado oeste de la intersección formada por la carretera asfaltada Ayacucho-San Francisco y la trocha carrozable Chacco-Quinua, a una distancia de $35 \mathrm{~km}$ al noroeste de la ciudad de Ayacucho. Presenta una suave pendiente y hacia a sus alrededores forma una amplia llanura que se extiende casi ininterrumpidamente hasta las inmediaciones del sitio arqueológico de Wari, ubicado a $10 \mathrm{~km}$ hacia el noroeste (Figuras 1, 2 y 3).

Actualmente la primera impresión que se tiene al caminar por estos terrenos, es no poder visualizar ningún tipo de estructura arquitectónica prehispánica, pues gran parte de las ellas están sepultadas, siendo únicamente visibles en la superficie algunos fragmentos de cerámica, restos líticos y material óseo fragmentado. Es notorio que el sitio se emplaza en un punto intermedio y estratégico para acceder rápidamente a las tierras altas de la puna (parte alta del pueblo de Quinua), y hacia los cálidos valles de Chacco y Huanta. Esta ubicación estratégica fue aprovechada desde las épocas prehispánicas y en la actualidad por las laderas del sitio aún quedan evidencias de caminos prehispánicos que se dirigen hacia los territorios referidos y hacia la zona de la selva del río Apurímac.

\section{Aspectos Geográficos y Antecedentes de InVestigación}

El sitio arqueológico de cerro Churucana se ubica en el valle de Ayacucho, al noreste del complejo arqueológico de Wari. El valle de Ayacucho está formado por la cuenca de Huarpa (ubicada hacia el norte) y la cuenca de Ayacucho o Huamanga (ubicada hacia el lado sur). Presenta una topografía accidentada con estrechas y profundas quebradas por donde discurren los ríos Huatatas, Muyurina,

1. Fue al inicio de la reapertura de zanjas para la sustitución de tuberías de agua potable que el personal técnico del Gobierno Regional de Ayacucho llegó a encontrar evidencias arqueológicas. Por este motivo, la Dirección Regional de Cultura de Ayacucho paralizó las obras y pidió que se efectúe un Monitoreo Arqueológico para la obra: "Ampliación y mejoramiento del sistema de agua potable y saneamiento en la zona rural del distrito de Quinua, provincia de Huamanga-Ayacucho. Sector "A": Muruncancha, Vista Alegre, Churucana, Huacahurara y Pampachacra”, el cual fue aprobado con la RDR Nro 20-DRC-AYA/MC. 
Chacco, Occopa, Lluncuna, Cachi, Pongora y Huarpa. (Fig. 3). Los territorios ubicados en los diversos pisos ecológicos, se caracterizan por poseer diferentes temperaturas, precipitación, radiación solar, humedad y condiciones de evaporación, determinando la existencia de diferentes tipos de vida vegetal y animal. Según la clasificación de Tosi (1960), Holdridge (1967) y Koppen (1948) se identifican los climas de estepa, clima frío boreal y clima frío de tundra seca de alta montaña. De otro lado, desde la época prehispánica, las comunidades andinas han implementado estrategias de subsistencia que les permitieron integrar los diferentes pisos altitudinales de manera complementaria.

El valle de Ayacucho cuenta con una diversidad de ecosistemas que van desde ambientes muy áridos hasta las tierras húmedas. Según la clasificación de zonas ecológicas realizadas por Pulgar (1981), está compuesto por las siguientes regiones: Yunga, Quechua, Suni, Puna y la región Jalca; de otro lado las zonas de vida natural que se encuentran son:

- Estepa espinoso - Montano Bajo Subtropical (ee-MBS), posee clima seco y templado frío, con un promedio anual de $250-600 \mathrm{~mm}$ de precipitación pluvial y una bio-temperatura media anual de $12^{\circ} \mathrm{C}$ a $17^{\circ} \mathrm{C}$. Abarca territorios desde los 2200 a $3000 \mathrm{msnm}$ y comprende las regiones Yunga y Quechua de la clasificación de Pulgar Vidal (1981) y la ecorregión serranía esteparia de Brack (1986). La vegetación muestra una diversidad de especies típicas como el cactus (bursera graveolens), tara (Caesalpinea tintórea), huarango (Acacia macracantha), pastos (Tillandsia sp.), algarrobo (Prosopis pállida), en las orillas del río y quebradas cálidas crecen los molles (Schinus molle), tuna (Opuntia ficus-indica), Cabuya (Agave americana), muña (Minthosthachys off mollis). Entre la fauna silvestre se encuentran el venado de cola blanca (Odocoileus virginianus), pequeños animales y numerosas aves. Se practica el cultivo del maíz (Zea Mays), pallares (Phaseolus vulgaris), cucúrbitas (Cucurbita maxima), y frutas como la guayaba (Psidium guayava) y lúcuma (Lúcuma bifera).

- Estepa-Montano Subtropical (e-MS): Abarca territorios ubicados entre los 3000-3400 msnm, corresponde a la región Quechua de la clasificación de Pulgar Vidal (1981) y a la ecorregión serranía esteparia de la clasificación de Brack (1986). El clima es sub húmedo y semi-frío, con 350-500 mm de precipitación promedio anual, la biotemperatura media anual es de $10^{\circ} \mathrm{C}-12^{\circ} \mathrm{C}$. La vegetación típica comprende el molle (Schinus molle), huarango (Acacia macracantha), cabuya (Agave americana), nopal (Opuntia ficus) y cardón (Cordia sp.). Los frijoles (Phaseolus vulgaris y Phaseolus lunatus), calabaza (Cucurbita maxima y Cucurbita moschata), ají (Capsicum sp.) y el maíz (Zea mays). Entre la fauna típica se tiene a la vizcacha (Lagidium peruanum), zorro (Dusicyon culpaeus), zorrillo (Conepatus sp.), gato montés (Felis jacobita) y el puma (Felis concolor).

- Bosque húmedo - Montano subtropical (bh-MS): Se encuentra entre los 3300 y 4000 msnm, comprende a la región Suni de la clasificación Pulgar Vidal (1981) y a la ecorregión serranía esteparia y puna de la clasificación de Brack (1986). Se caracteriza por presentar un clima húmedo y semi frío, con $600-800 \mathrm{~mm}$ de precipitación promedio anual y $6^{\circ} \mathrm{C}$ a $10^{\circ} \mathrm{C}$ de biotemperatura media anual, presentándose por temporadas temperaturas críticas o de congelación $\left(0^{\circ} \mathrm{C}\right)$, intensas granizadas y nevadas. La vegetación natural es arbórea y está constituida por bosques residuales de queñua (Polylepis incana, Polylepis sp), kiswar (Buddleia sp), titanka (Puya Raimondi), pastos naturales (Festuca, Stipa, Calamagrostis y Poa). Entre los cultívos andinos característicos podemos mencionar a la papa (Solanum tuberosum), oca (Oxalis tuberosum), olluco (Ullucus tuberosus) y mashwa (Tropaeolum tuberosum), y granos como la quinua (Chenopodium quinoa) y cañihua (Chenopodium pallidicaule).

- Páramo muy húmedo-Subalpino Subtropical (pmh-SaS): Se ubica entre los 3900 y 4500 msnm, incluye la región Suni de la clasifiacion de Pulgar Vidal (1981) y a la ecoregión Puna y Paramo en la clasificación de Brack (1986). Presenta clima muy húmedo y frío, con 700 a 800 mm de precipitación 
promedio anual y $3^{\circ} \mathrm{C}$ a $6^{\circ} \mathrm{C}$ de biotemperatura anual, presentándose temperaturas de congelación en las partes altas de Huanta y Huamanga. La mayor parte de la vegetación son pastos duros como Ichu (Stipa sp, Festuca sp, y Calamagrostis sp.), tola (Lepidophyllum o Baccharis). Entre la fauna los más importantes son el guanaco (Lama guanacoe) y la vicuña (Vicugna vicugna), además de la alpaca (Lama pacus) y la llama (lama glama).

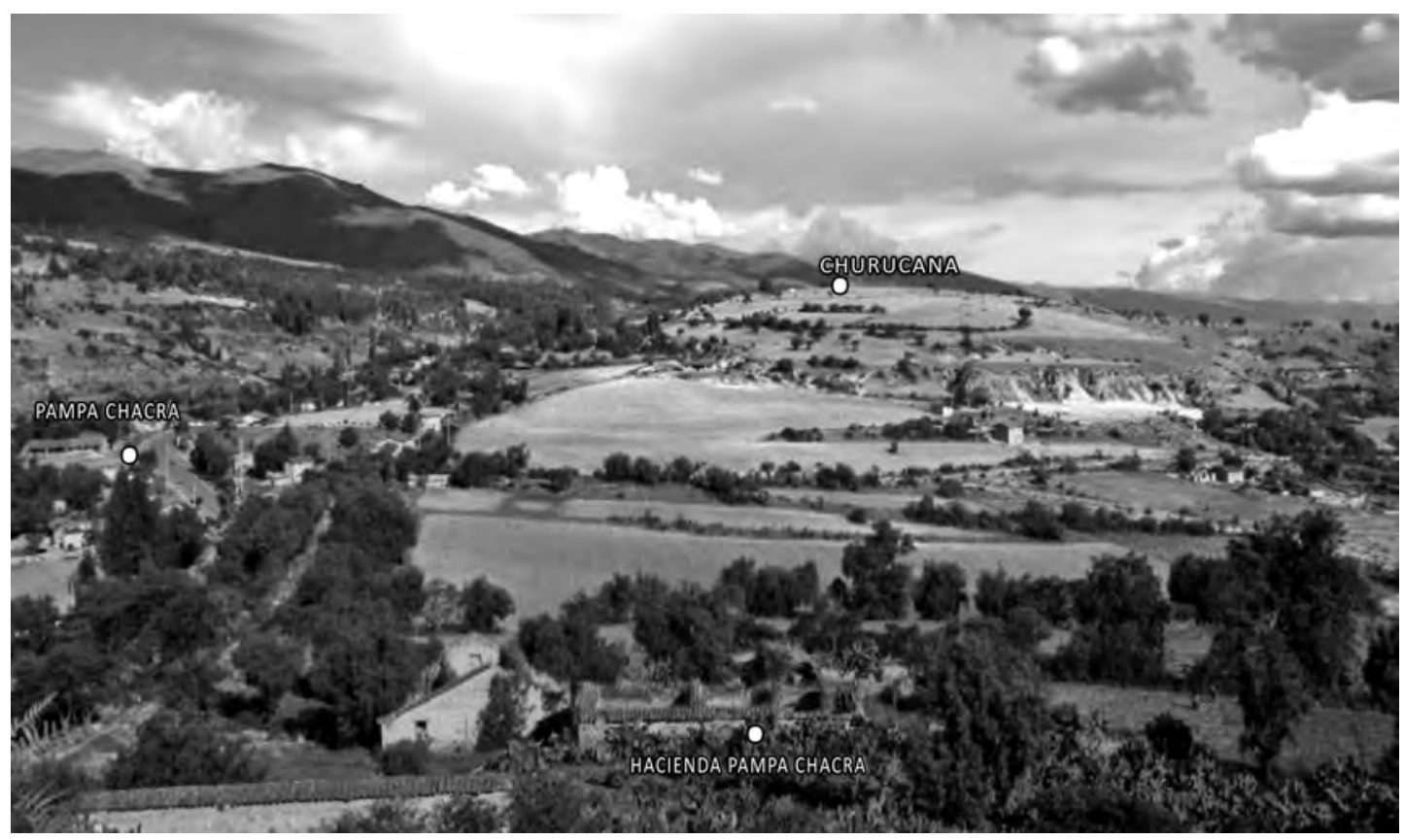

Figura 1. Vista panorámica del cerro Churucana y de la comunidad de Pampachacra

Las primeras referencias del sitio arqueológico corresponden a Bonavia (1966), quien señala que: "Churukana es un sitio grande e importante del estilo Huarpa (...) El sitio se encuentra en la cumbre y en la ladera norte del cerro. Está totalmente sembrado de trigo, pero hay ralos arboles de molle en los terrenos. No hay restos de construcciones pero si hay montones de piedra suelta. Hay morteros y porras de piedra. La gran mayoría de los tiestos decorados corresponden al estilo Huarpa; hay unos pocos que pertenecen al grupo A de Huari (Acuchimay), no se encontraron tiestos posteriores".

Por su parte Benavides (1976), menciona que en la superficie del sitio se encuentra cerámica del Periodo Intermedio Temprano. En otra publicación refiere que en el lugar también existe cerámica del Periodo Formativo (Benavides 1983). Por su parte Isbell (1991) también menciona que en el sitio de Churucana hay presencia de cerámica formativa y posibles evidencias de estructuras de adobes.

Siguiendo las descripciones hechas por los anteriores autores, Pérez (1999) también manifiesta que en dicho lugar se encuentran fragmentos de cerámica Formativa, Huarpa y Wari. De otro lado, Lumbreras (2007) compara el cerro Churucana con el sitio arqueológico de Ñawinpuquio, y plantea que el primero de los mencionados se encuentra ubicado en una zona adecuada para el control de agua, campos de cultivo y cerca de las vetas de arcilla para la fabricación de la cerámica.

El año 2011 Cavero realiza trabajos de monitoreo arqueológico para las obra del mejoramiento y sustitución de tuberías de agua potable de las localidades de Muruncancha, Pampachacra, Huacaurara 
y Vista Alegre. En el desarrollo de los trabajos mencionados se hallaron dos sectores con arquitectura en base al empleo de adobes y cerámica del Periodo Formativo, asimismo cistas asociadas a materiales del Periodo Intermedio Tardío y Horizonte Medio.

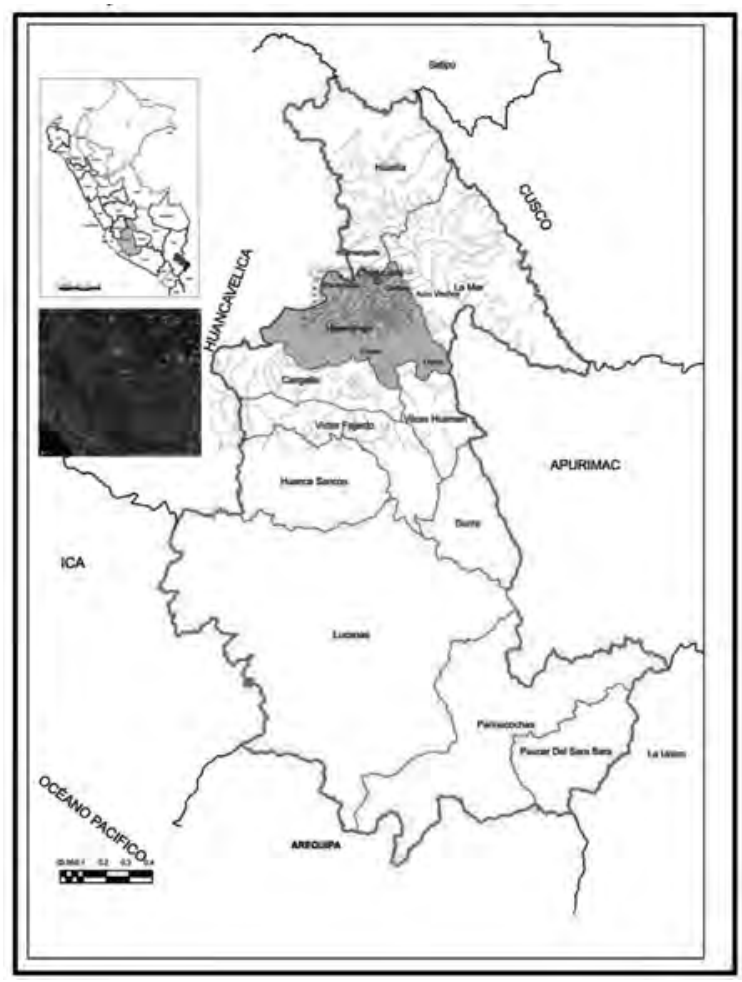

Figura 2. Mapa de ubicación del sitio arqueológico del cerro Churucana

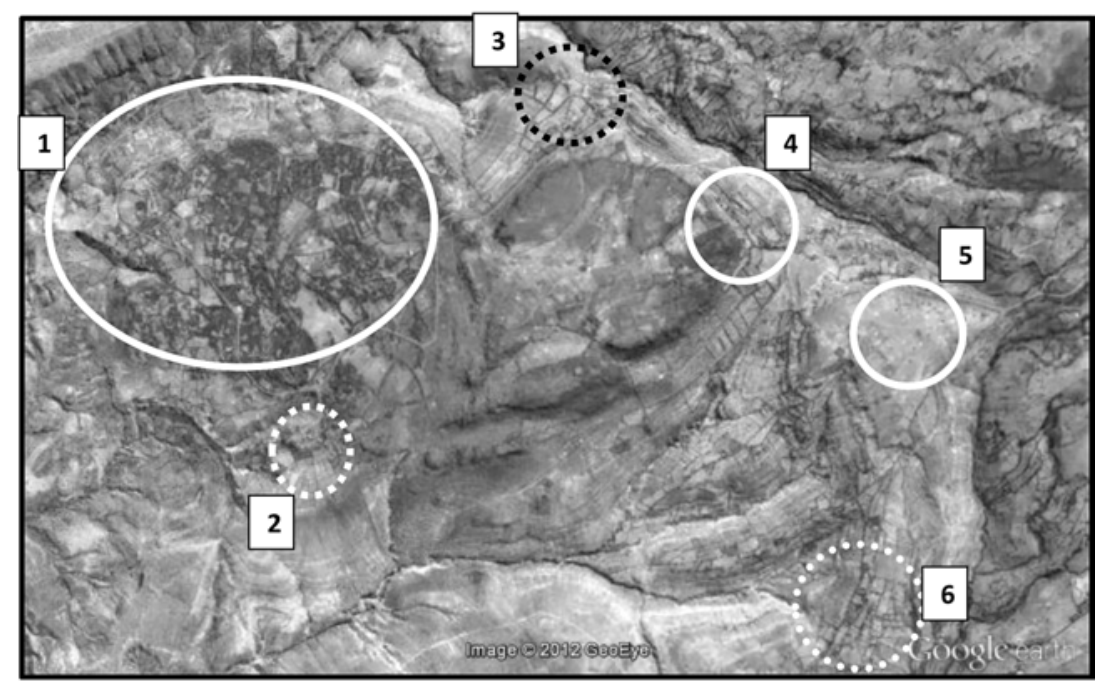

Figura 3: Vista aerea del territorio circundante a Churucana : (1) sitio arqueologico de Wari. (2) anexo de Vista Alegre. (3) anexo de Huacahurara. (4) anexo de Pampachacra. (5) Churucana y (6) anexo de Muruncancha. (Elaboracion propia, adecuado de: www. Google Earth 2012). 


\section{Intervenciónes Arqueológicas en Churucana}

El trabajo de campo se inició con un reconocimiento general del sitio, especialmente en la parte alta de la colina, punto donde se encuentra instalado desde los años 70-80 un reservorio que abastece de agua potable a las localidades de Churucana, Pampachacra, Vista Alegre, Muruncancha y Huacahurara. Luego se efectuó un reconocimiento de los puntos por donde discurren las tuberías de agua potable, las mismas que debían ser reaperturadas con la finalidad de sustituir las tuberías de PVC que conducen el agua potable a las localidades antes mencionadas. El objetivo central de este reconocimiento fue identificar las principales concentraciones de restos de material cultural y replantear el trabajo de ingeniería, toda vez que el expediente técnico consideraba que la reapertura de las zanjas serian efectuadas con el empleo de maquinaria pesada, por lo cual, al momento de asumir la dirección del Monitoreo Arqueológico y con la respectiva autorización de la Dirección Regional de Cultura de Ayacucho, se modificó dicha propuesta y se sugirió que la reapertura se proceda con el empleo de herramientas manuales y con un monitoreo arqueológico permanente.

Este procedimiento de trabajo nos permitió registrar y estudiar las secciones de los perfiles de las zanjas que eran materia de reapertura y a la vez nos permitió identificar y registrar los puntos donde se detectó la presencia de restos arqueológicos. En estos casos, se paralizaron las obras y previa coordinación con la Dirección Regional de Cultura, se decidió la recuperación de las evidencias arqueológicas, para cuyo efecto se tuvo que cuadricular los puntos con evidencias identificadas. En el tramo de las tuberías que se dirigen hacia la localidad de Muruncancha y también en el caso del tramo que se dirige hacia las localidades de Pampachacra y Huacahurara, se encontraron cuatros puntos con presencia de restos arqueológicos directamente adosados a los perfiles de las zanjas, por lo cual, se procedió a la recuperación de los restos arqueológicos, siguiendo los lineamientos indicados por el personal de la DRC-Ayacucho. Las unidades fueron inicialmente de $2 \mathrm{~m}$ x $2 \mathrm{~m}$ y fueron numeradas correlativamente como UEA 1, 2, 3 y 4. Todas ellas fueron excavadas hasta la capa estéril. Todo el proceso de intervención fue debidamente registrado con la finalidad de recoger mayor cantidad de información posible, este sistema consistió en desarrollar las tres modalidades registro: descriptivo, gráfico y fotográfico.

\section{UBICACIÓN DE UNIDADES DE EXCAVACIONES ARQUEOLOGICAS}

\begin{tabular}{|c|c|c|c|}
\hline $\begin{array}{c}\text { Nro } \\
\text { Unidad }\end{array}$ & $\begin{array}{c}\text { Ubicación } \\
\text { UTM Norte }\end{array}$ & $\begin{array}{c}\text { Ubicación UTM } \\
\text { Este }\end{array}$ & Dimensión \\
\hline $\mathbf{1}$ & 8555406 & 590960 & $2 \mathrm{mts} \times 2 \mathrm{mts}$ \\
\hline $\mathbf{2}$ & 8555404 & 590946 & $2 \mathrm{mts} \times 2 \mathrm{mts}$ \\
\hline $\mathbf{3}$ & 8555359 & 590944 & $2 \mathrm{mts} \times 2 \mathrm{mts}$ \\
\hline $\mathbf{4}$ & 8555393 & 590949 & $2 \mathrm{mts} \times 2 \mathrm{mts}$ \\
\hline
\end{tabular}




\section{DESCRIPCIÓN DE LAS UNIDADES DE EXCAVACIONES ARQUEOLÓGICAS: UNIDAD DE EXCAVACIÓN N ${ }^{\circ} 1$}

Ubicación: Parte superior de la colina y hacia el lado noreste del reservorio de agua potable. La secuencia estratigráfica hallada es la siguiente:

Capa Superficial: Tierra removida por la actividad agrícola, cubierta por partes con gramíneas y restos de chala. Presenta un color marrón claro, tendiente por partes hacia el color gris. Se observan raíces y piedrecillas dispersas, su textura es granulosa. Posee un espesor de 15 a $20 \mathrm{~cm}$. En la superficie se evidencian materiales arqueológicos variados correspondientes al Periodo Intermedio Tardío, Horizonte Medio y Periodo Intermedio Temprano, mezclados con basura moderna (Figura 4).

Capa A: Terreno cultivable posee un espesor de 15-20 cm, es de color gris claro. Su consistencia es suelta, de textura granulosa y se compone de gravilla, piedras y raíces. Presenta abundantes fragmentos de cerámica, restos óseos, líticos y material moderno. Hacia el lado sur y este de la unidad de excavación se halló una concentración de piedras y tierra de color gris semicompacta (Figura 5).

Capa B: Presenta un color gris claro y por partes tiende a presentar un color marrón, posee un espesor de $35-40 \mathrm{~cm}$ y su consistencia es compacta, con presencia de inclusiones de gravilla, grava y restos arqueológicos removidos, destacando la presencia de huesos de camélidos. Hacia el lado norte de la unidad se define la existencia de una cabecera de muro con orientación de NE-SW, el cual al parecer es de manufactura reciente, toda vez que debajo de esta estructura se halló una botella de vidrio y materiales modernos. La tierra se encuentra removida y se encuentran gran cantidad de piedras sueltas de tamaños variados (Figura 6).

Capa C: Tierra orgánica de color marrón a marrón grisáceo, de consistencia semisuelta, su granulometría es fina a mediana y se caracteriza por la escasa presencia de piedras y la considerable disminución de material cultural, los fragmentos cerámicos hallados corresponden al Periodo Intermedio Temprano (Huarpa), mientras los restos óseos de camélidos se encuentran muy deteriorados y removidos.

Capa D: Tierra orgánica de color negro, semicompacta y con una granulometría fina y mediana. Por partes se observa las huellas de la remoción del terreno y los escasos materiales arqueológicos son datables a los Desarrollos Regionales.

Capa E: Tierra de color negro claro, de textura granulosa y de consistencia semicompacta. Se encuentra en partes removida y los materiales culturales hallados son escasos fragmentos de cerámica correspondiente a los desarrollos regionales.

Capa F: Tierra de color marrón claro, de textura granulosa. Presenta una consistencia semicompacta y en la parte final se halló un piso de piedras planas dispuestas horizontalmente, probablemente correspondientes al Periodo Formativo (Figura 7).

Capa G: Tierra marrón rojiza y de consistencia compacta, corresponde a la capa estéril sin ningún tipo de evidencias arqueológicas. 


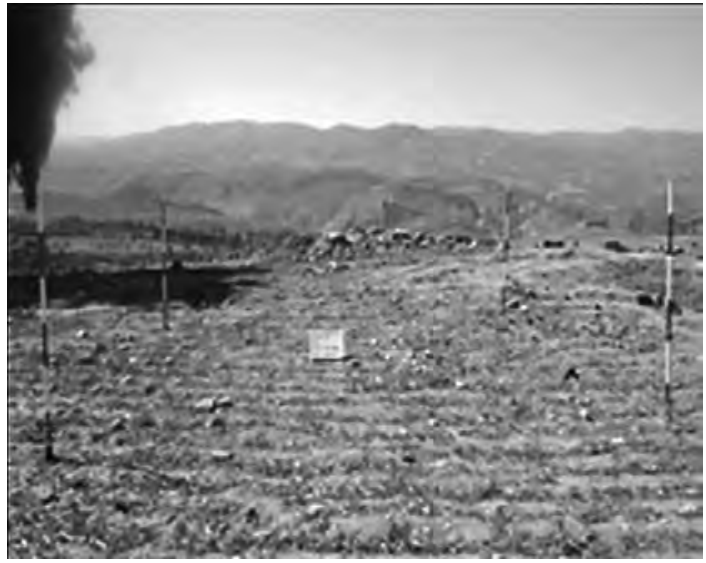

Figura 4: Unidad previa a su excavación.

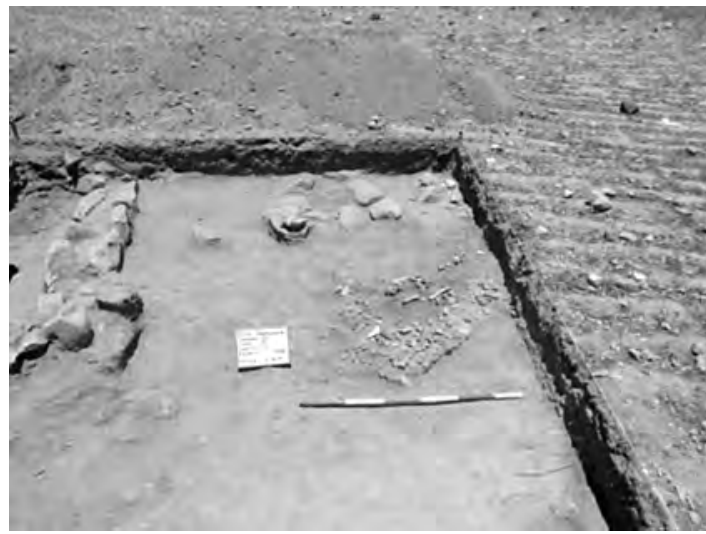

Figura 6: Detalle de la capa B.

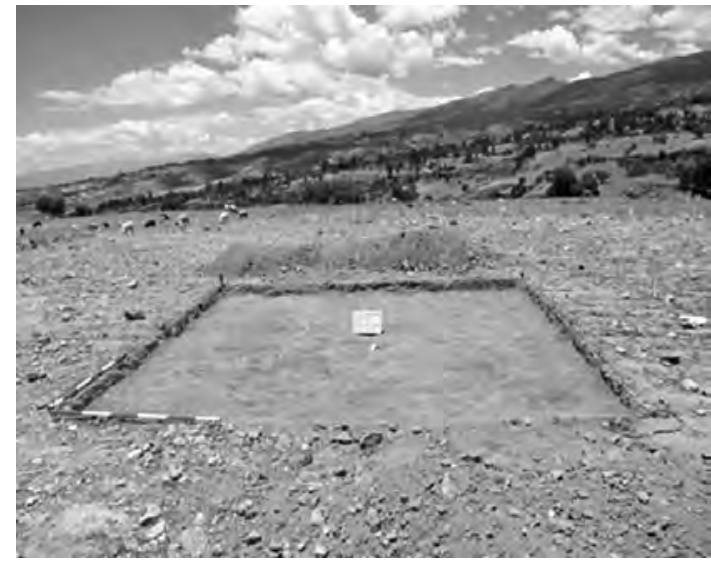

Figura 5: Detalle del inicio de la capa A

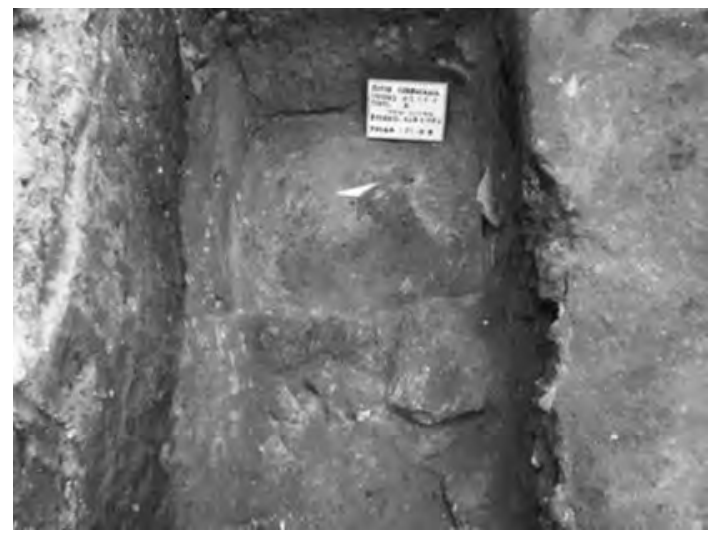

Figura 7: Detalle empedrado con lajas planas. 

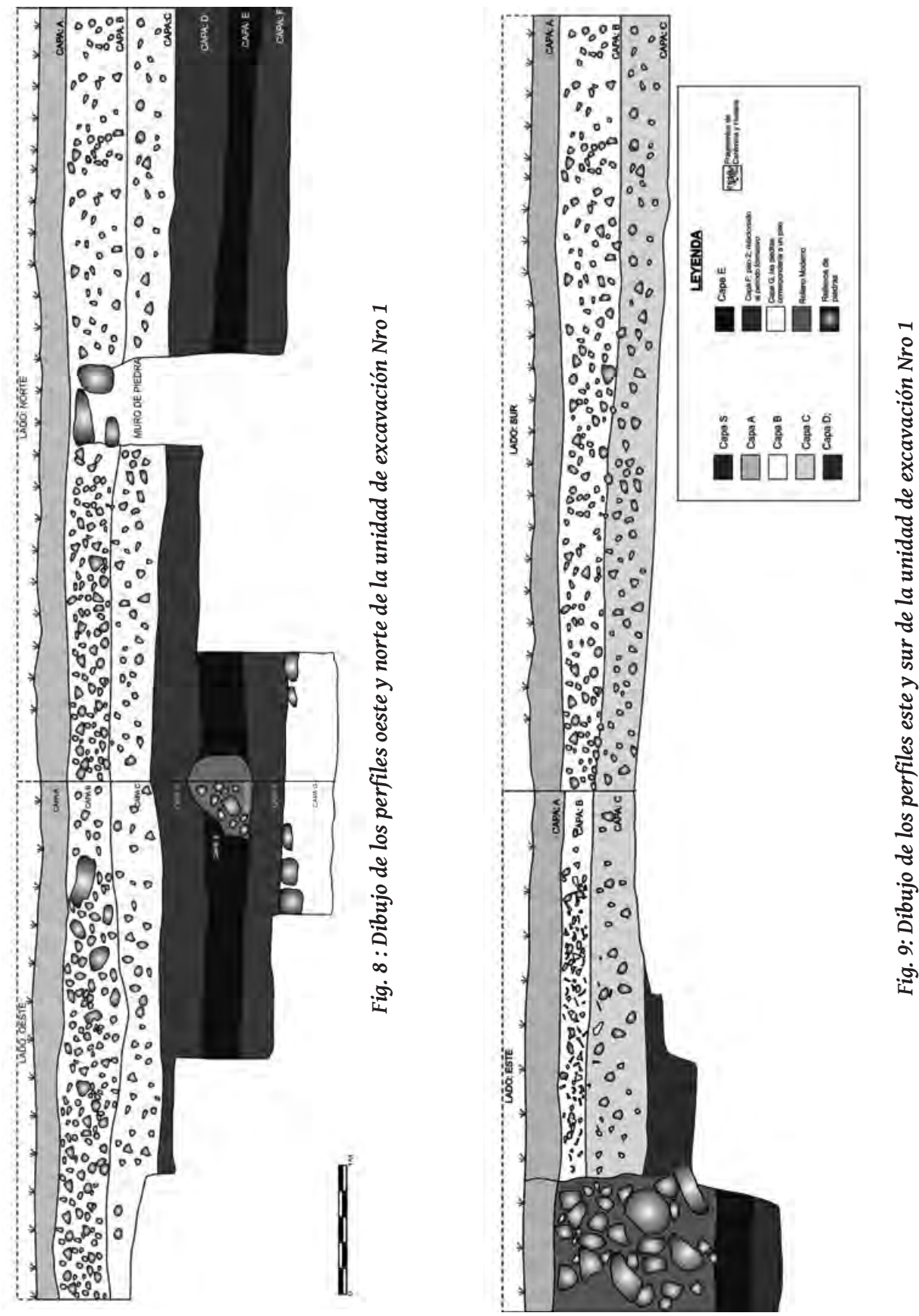


\section{UNIDAD DE EXCAVACIÓN N²}

Ubicación: Se ubica en la parte superior de la colina, hacia el lado norte del reservorio de agua. Las características que presenta la estratigrafía es la siguiente:

Capa superficial: Compuesta por tierra removida por las actividades agrícolas, su consistencia es suelta y se encuentran fragmentos de cerámica correspondientes al Horizonte Medio y al Periodo Intermedio Temprano. (Ver figura 10).

Capa A: Tierra de cultivo de color marrón claro, de consistencia suelta, textura granulosa con presencia de gravilla, grava y raíces, u espesor es de $30 \mathrm{~cm}$ y contiene abundante material arqueológico. En esta capa se inicia a visualizar los tubos de PVC que conducen el agua potable hacia las comunidades de Pampachacra y Huacahurara.

Capa B: Tierra de color marrón, de consistencia compacta, de textura granulosa, con presencia de inclusiones de gravilla y grava. El espesor alcanzado es de $35 \mathrm{~cm}$ y también se encuentra muy disturbado y removido, se encuentra abundante material de desmonte conteniendo materiales arqueológicos variados (Ver figura 11)

Capa C: Tierra orgánica de color marrón, de consistencia semisuelta y textura granulosa con escasa piedras sueltas. Se encuentran huesos de camélidos y fragmentos de cerámica correspondiente al Periodo Intermedio Temprano.

Capa D (Piso 1): Tierra arcillosa de color rojo y de consistencia compacta. Corresponde al piso 1 , se dispone de modo horizontal en gran parte de la unidad de excavación y posee 10-15 cm de espesor y fue instalado para sellar la estructura de adobe que se encuentra debajo. Los materiales arqueológicos hallados son muy escasos.

Capa E: Tierra de color marrón, de textura granulosa y de consistencia semicompacta. Se trata de un relleno antrópico con fines de sellar de manera cuidadosa el recinto construido con adobes de formas semirectangulares y semiesféricos, unidos con mortero de barro, presenta enlucido de barro y restos de pintura. El relleno no contiene material cultural alguno, solamente se compone de tierra, fragmentos de adobes y piedras de tamaños variados.

Capa F: (Piso 2). Se trata de un piso de diatomita que posee un espesor de 10-15 cm; hacia el lado Oeste presenta una coloración blanquecina, sin embargo, en otras áreas adquiere una coloración rojo oscuro-guindo y se encuentra en mal estado de conservación. Hacia el lado este se halló una pirca que separa el relleno del muro de adobes y no se encuentra el piso de diatomita. Debajo del piso se encontró un relleno de $20-30 \mathrm{~cm}$ de espesor, el cual posee similares características al otro relleno hallado en la capa E, pero con poca presencia de material cultural, básicamente constituidos por fragmentos de cerámica Huarpa. (Figura 12 y 13)

Capa G: (Piso 3): Se trata de otro piso de color marrón-rojizo, debido a actividad de quema, por sectores presenta un color amarillo, su textura es granulosa y de consistencia semicompacta. Se trata del primer piso asociado a la época de construcción del muro de adobe; los fragmentos de cerámica hallados corresponden al Periodo Formativo.

Al lado este se halló otra sección de una estructura semicircular el cual también está construido con adobes de formas semirectangulares. Lamentablemente al no haberse obtenido el respectivo permiso para poder ampliar nuestras excavaciones, no logramos conocer su real extensión y demás características que posee. (Figura 16). 
Capa $\mathbf{H}$ capa final / afloramiento rocoso: Tierra de color beige, correspondiente a la formación natural o afloramiento rocoso, se dispone por debajo del piso 3. El nivel excavado no contiene material arqueológico alguno (Figura 17).

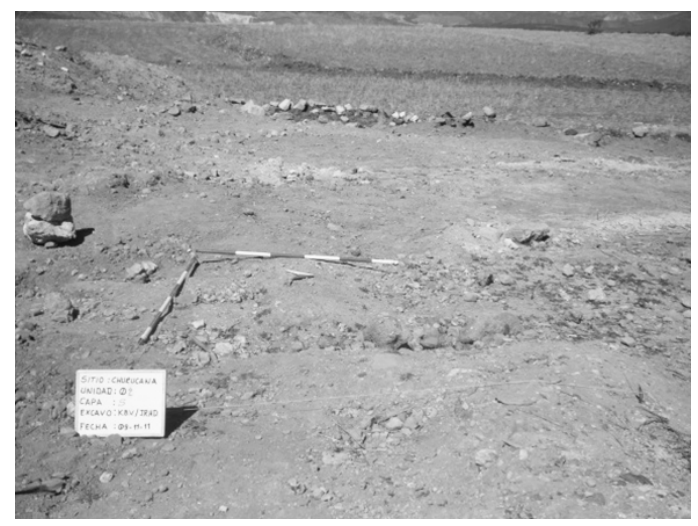

Figura 10: Unidad 2 previa a su excavación.

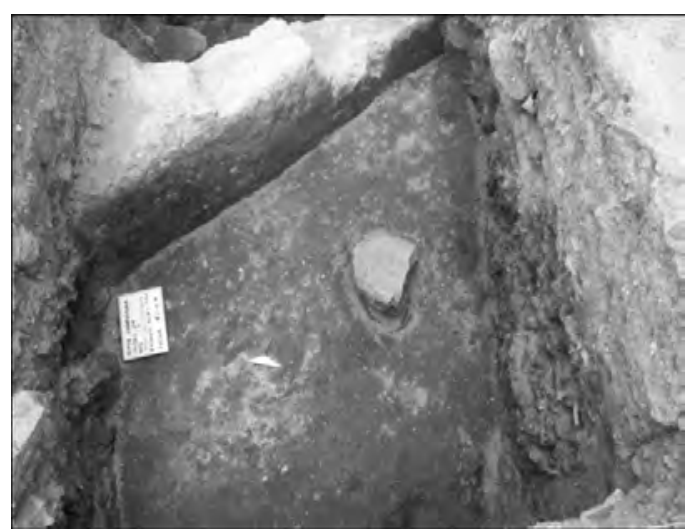

Figura 12: Vista del muro construido con adobes y del piso 2.

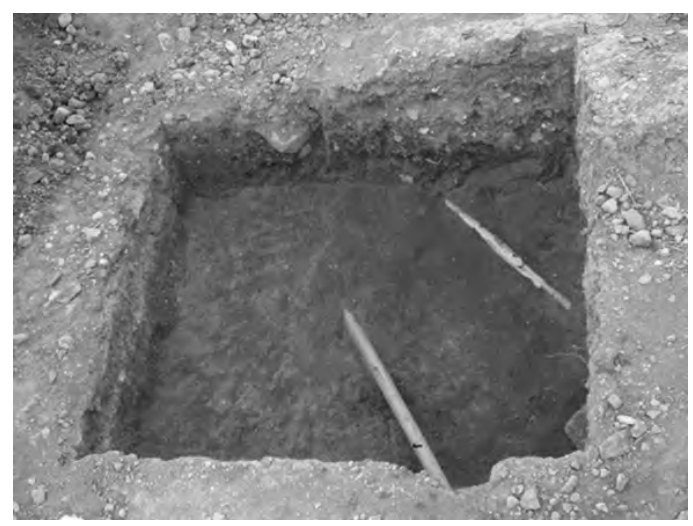

Figura 11: Capa B: presencia de tubos de PVC.

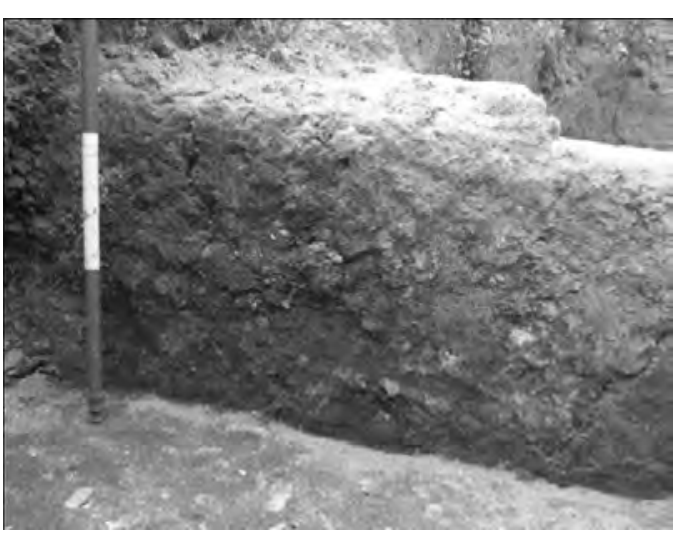

Figura 13: Detalle del paramento del muro de adobes y el piso Nro 2 de la epoca Huarpa. 


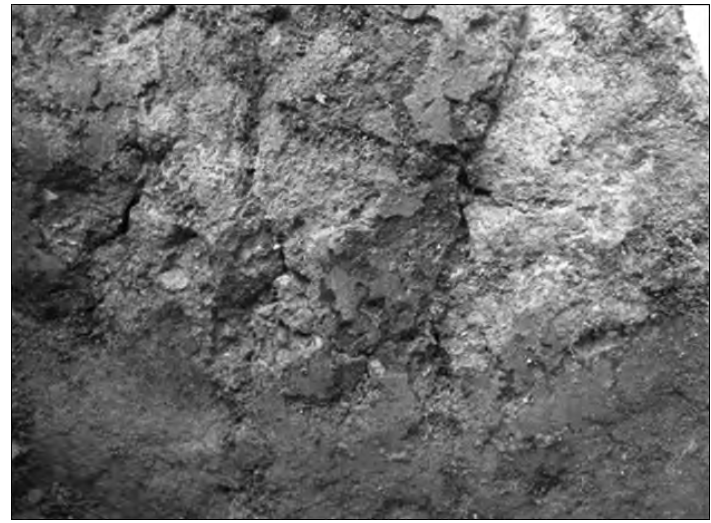

Figura 14: Restos de pintura de color blanco y Marrón hallados en el muro de adobes.

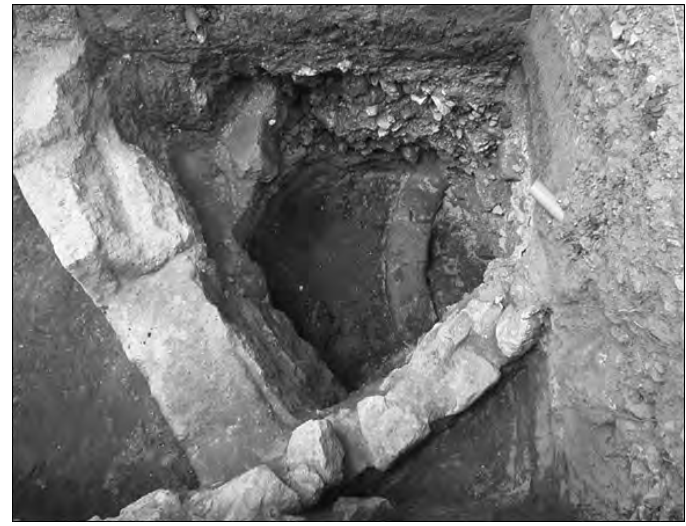

Foto 15: Sección de estructura circular construido con adobes semirectangulares.

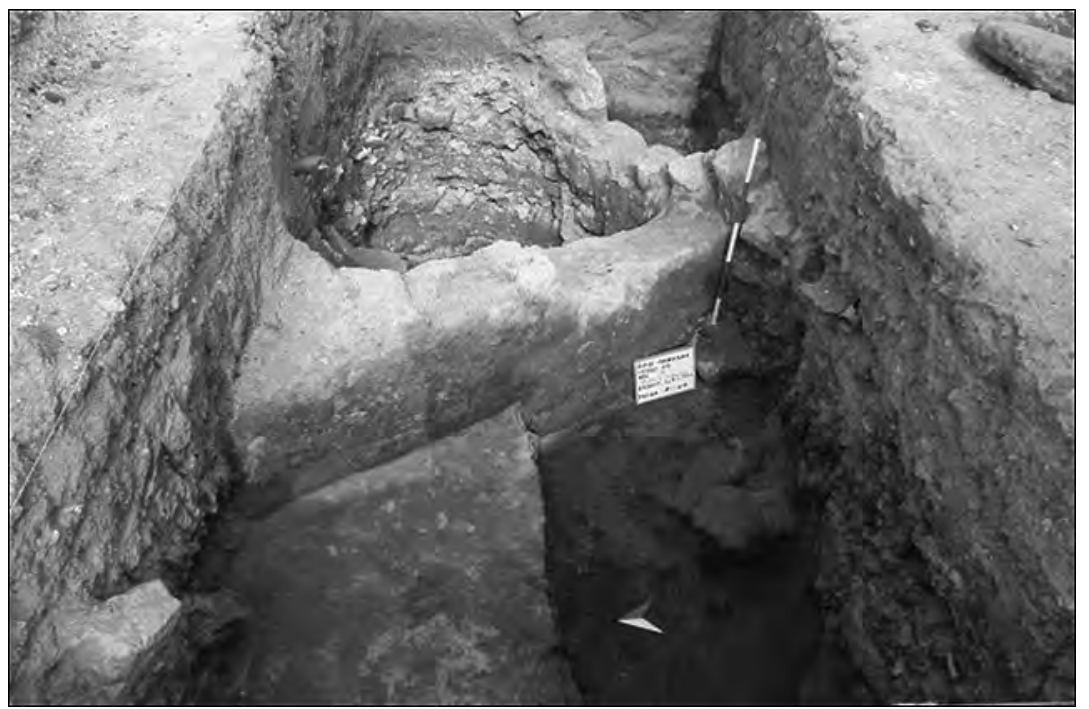

Figura 16: Muro construido con adobes (Periodo Formativo) y secuencia de pisos asociados. 

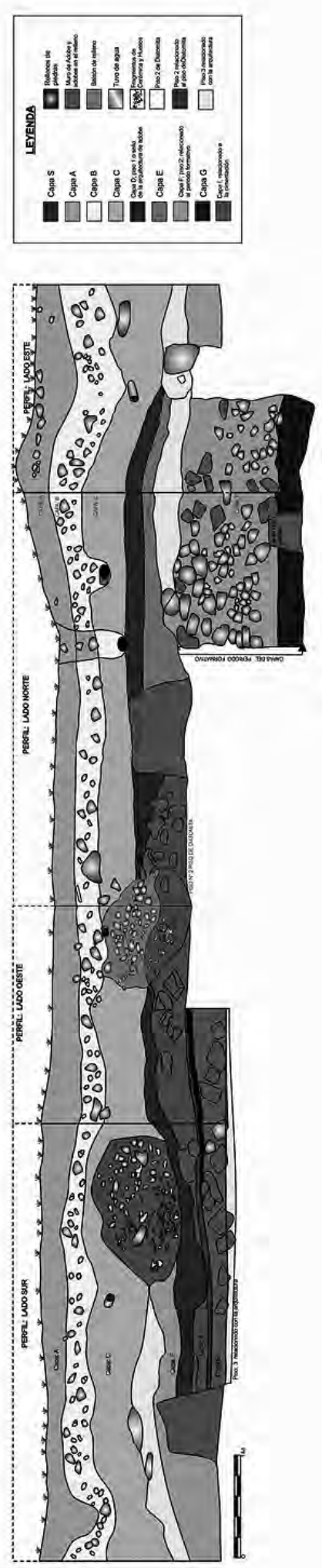
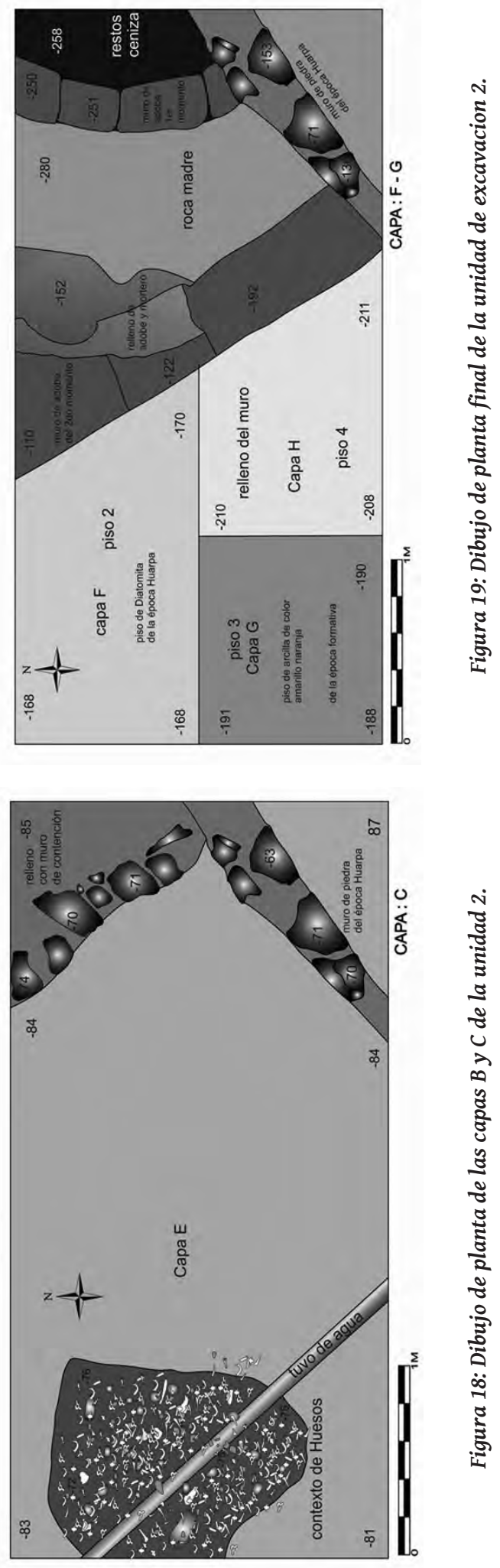


\section{UNIDAD DE EXCAVACIÓN Nº 3}

Se ubica en la parte media y sur de la colina. Se decidió su apertura debido al descubrimiento de un alineamiento de piedras con mortero de barro en un punto del perfil de la zanja que contiene las tuberías de PVC que abastece de agua potable a la comunidad de Muruncancha. Las medidas iniciales de la unidad fueron de $2 \mathrm{~m} \times 2 \mathrm{~m}$ posteriormente se amplió para poder definir las tumbas que aparecieron.

Capa Superficial: Está compuesta por tierra orgánica cultivable muy removida, su consistencia es suelta, de granulometría fina y mediana. Se hallaron evidencias arqueológicas variadas, (Figura 20).

Capa A: Tierra cultivable de color marrón claro, de consistencia suelta y textura granulosa con presencia de gravilla, grava y raíces. Su espesor es de $20 \mathrm{~cm}$ y contiene material arqueológico variado.

Capa B: Tierra de color marrón, de consistencia semicompacta y textura granulosa con inclusiones de gravilla y grava. Su espesor es de 25 a $30 \mathrm{~cm}$, contiene diversas evidencias arqueológicas, destacando fragmentos de cerámica, cimentaciones de estructuras arquitectónicas construidas de piedras y barro, contextos de tumbas y huesos de camélidos datables al periodo de los Desarrollos Regionales (Figuras 21 al 25).

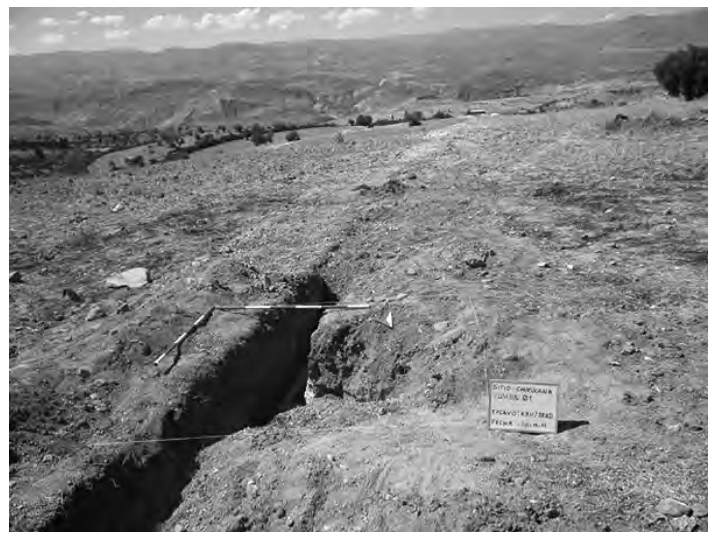

Figura 20: Unidad 3 previa a su excavación.

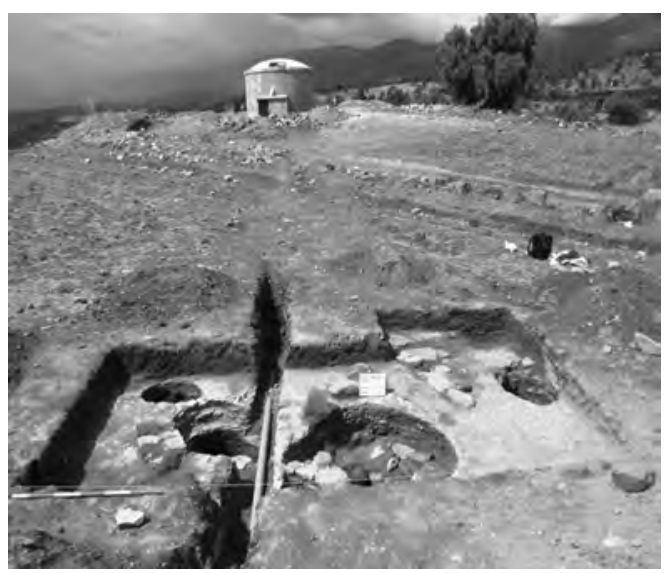

Figura 22: Final de excavación de unidad 3.

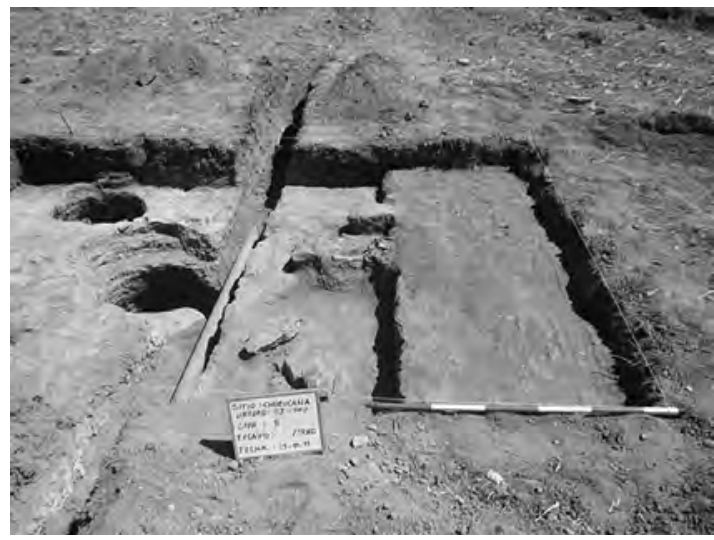

Figura 21: Proceso de excavación de la capa B

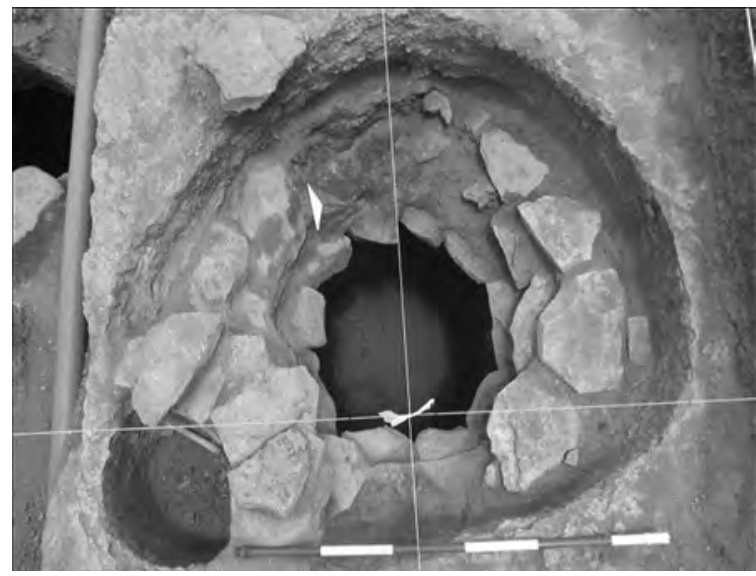

Figura 23: Detalle de la tumba 1. 


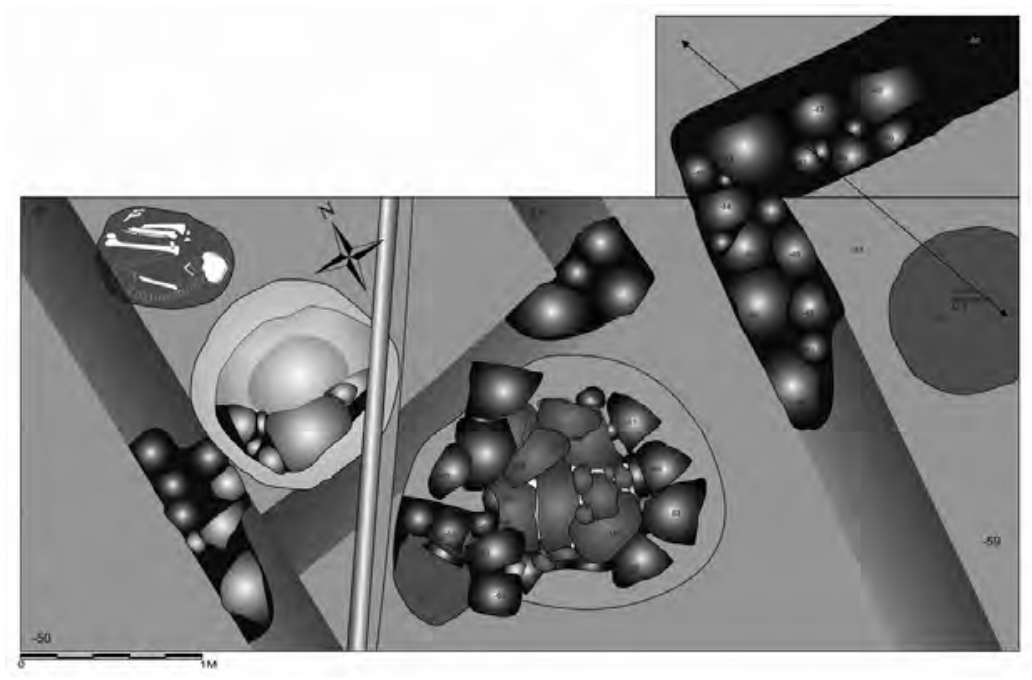

Figura 24: Dibujo de planta de contextos arqueológicos hallados en la capa B de la unidad 3.

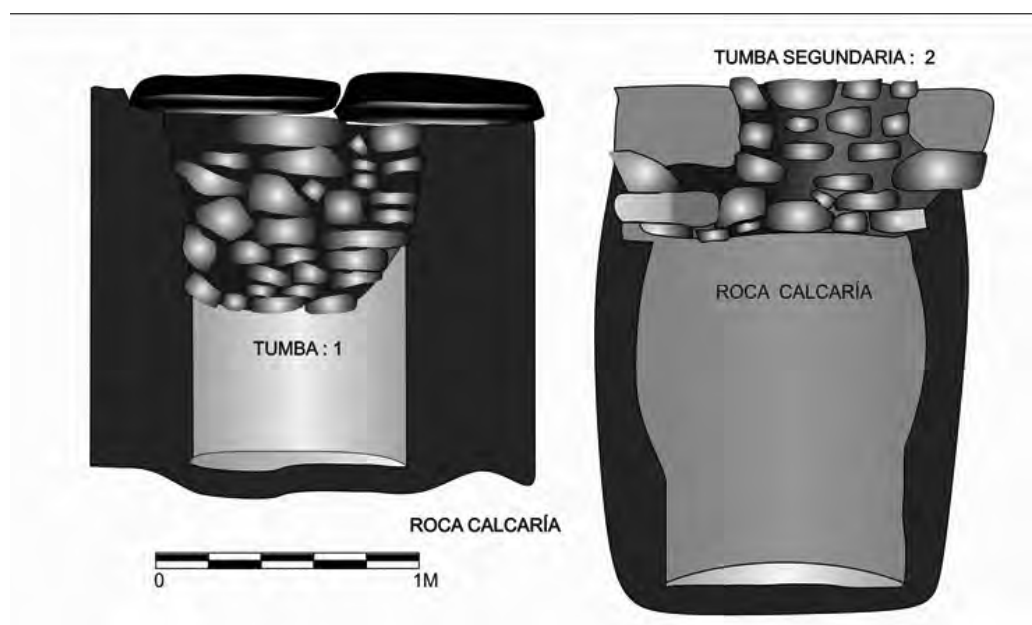

Figura 25: Dibujos de paramentos de las Tumbas 1 y 2 hallados en la unidad 3. 


\section{UNIDAD DE EXCAVACION N ${ }^{\circ} 4$}

Se ubica en la parte superior de la colina, y sus medidas finales fueron de $2.5 \mathrm{~m}$ x $5.50 \mathrm{~m}$, la secuencia estratigráfica definida es la siguiente:

Capa superficial: Tierra removida y desmonte de material moderno, se encuentra muy compactada y no se evidencian restos arqueológicos en su superficie (Figura 26)

Capa A: Tierra orgánica, corresponde a la tierra de cultivo agrícola, presenta una coloración marrón claro, su consistencia suelta, textura granulosa con presencia de gravilla y grava. Posee un espesor de 20 a $25 \mathrm{~cm}$ y contiene abundante material arqueológico, correspondiente al Horizonte Medio e Intermedio Tardío (Figura 27)

Capa B: Tierra de color marrón, se trata de un relleno de consistencia semicompacta, de textura granulosa, con presencia de inclusiones de gravilla y grava. Su espesor es de $35 \mathrm{~cm}$. Se encuentra regular cantidad de fragmentos de cerámica del Horizonte Medio y del Periodo Intermedio Temprano.

Capa C (piso 1): Piso de tierra de color marrón oscuro, de consistencia semicompacta, con escasa presencia de material arqueológico. Su espesor es de $15 \mathrm{~cm}$ aproximadamente.

Capa D: Tierra de color marrón oscuro, de consistencia semicompacta, utilizada para sellar la parte externa del muro de adobes. Presenta un espesor de $30-35 \mathrm{~cm}$, las evidencias arqueológicas son escasas y son de la época Huarpa (Figura 28).

Capa E: Tierra de color marrón, de textura granulosa de consistencia compacta; se trata de un relleno cuidadosamente colocado en la parte externa del muro de adobes, se tuvo especial cuidado en no dañar el paramento del muro. El espesor del relleno es de aproximadamente $1 \mathrm{~m}$ de altura en la parte externa del recinto arquitectónico y está constituido por fragmentos de adobes, piedras de tamaños variados y tierra. Presenta escasa evidencia cultural, destacando los fragmentos de cerámica del Periodo Intermedio Temprano (Huarpa). En la parte interna del recinto el relleno llega a tener solamente una altura de $40 \mathrm{~cm}$ de altura, al igual que en la parte externa, en el interior el relleno está constituido por los mismos tipos de materiales pero el porcentaje de tierra es mayor, asimismo, se encuentra poco material arqueológico (Figuras 29 y 30).

Capa F: (piso 2): Viene a ser el piso que se encuentra en el interior del recinto arquitectónico. Está constituido por tierra de color marrón de consistencia semicompacta, tiene un espesor de $20 \mathrm{~cm}$, no hay restos arqueológicos (Ver figura 31).

Capa G: Relleno ubicado al interior del recinto arquitectónico, está conformado por tierra de color marrón, de textura granulosa y consistencia semicompacta, piedras de tamaños variados y abobes fragmentados; contiene escaso material arqueológico, destacando fragmentos de cerámica domestica correspondiente al Periodo Formativo (Figura 32.)

Capa H: Tierra de color beige, de textura granulosa de consistencia suelta. Se trata de un relleno dispuesto para nivelar el suelo y sobre ella se procedió a edificar los muros de adobes que forman parte del recinto arquitectónico. No se encontraron evidencias arqueológicas de ningún tipo.

Capa I (piso 1): Se trata de un piso que se dispone en la parte externa del recinto arquitectónico. Presenta un espesor de 10-15 cm y es de color marrón y su consistencia es semicompacta. El material arqueológico hallado corresponde al Periodo Formativo, (Figuras 46-49). Debajo de este piso se encuentra ya el afloramiento Rocoso. 


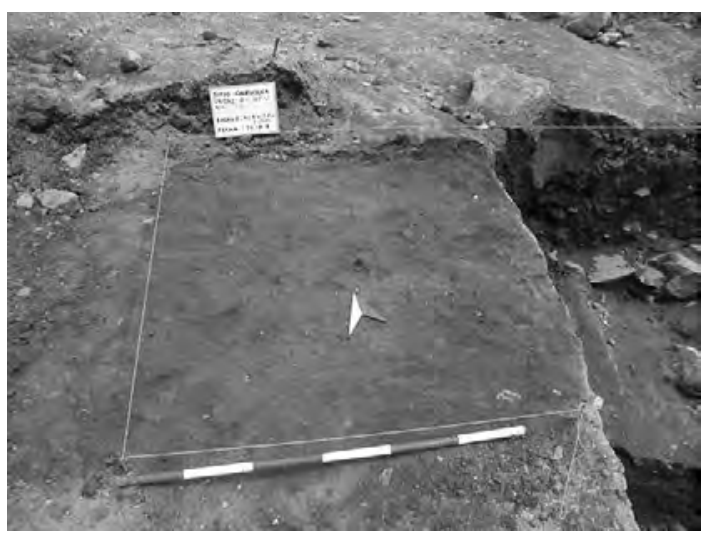

Figura 26: Final de la Capa superficial.

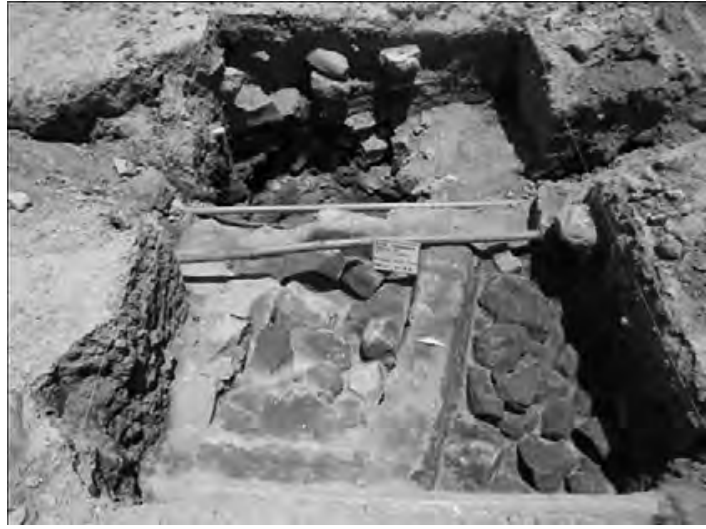

Figura 28: Capa D asociado a muro de adobe y recinto construido con muros de adobes.

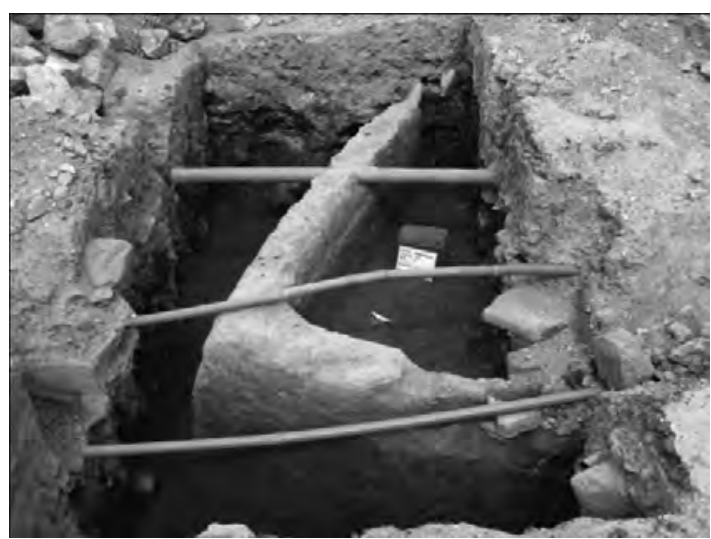

Figura 30: Capa F, recinto y Piso 2 asociado

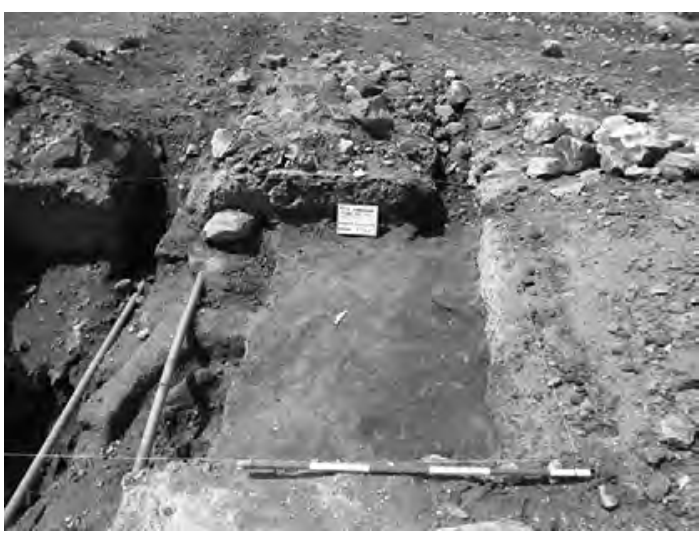

Figura 27: Capa A en la ampliación sur.

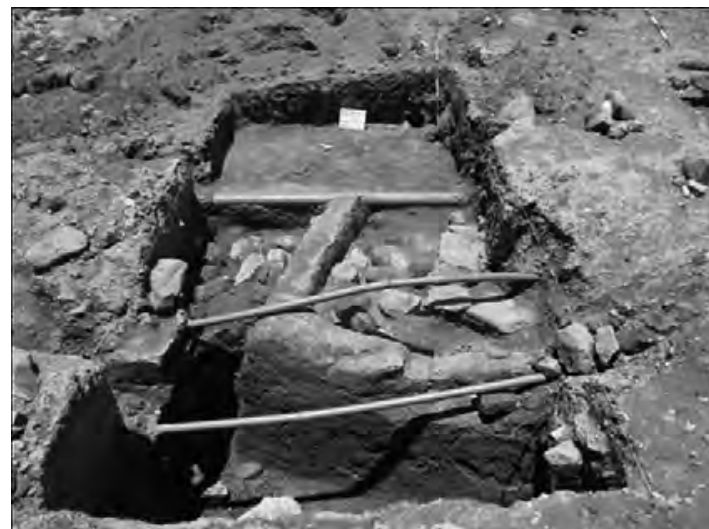

Figura 29: Capa E, detalle de Paramento del relleno de fragmentos de adobes, piedras y tierra

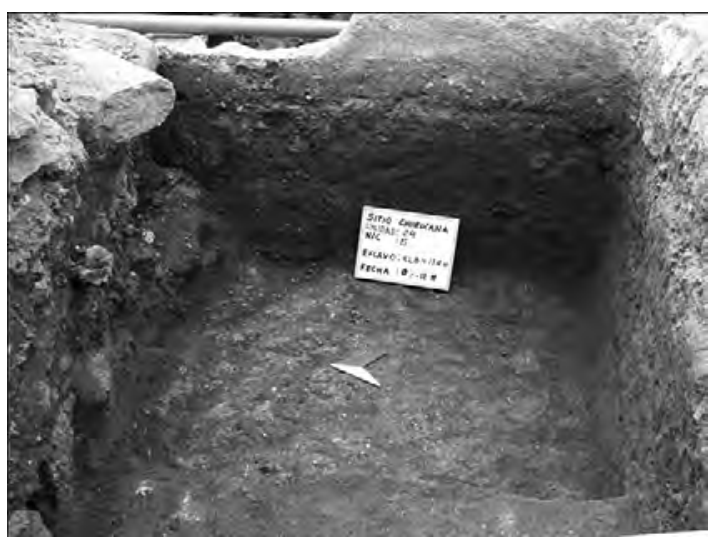

Figura 31: Piso 2 en el interior del recinto. 

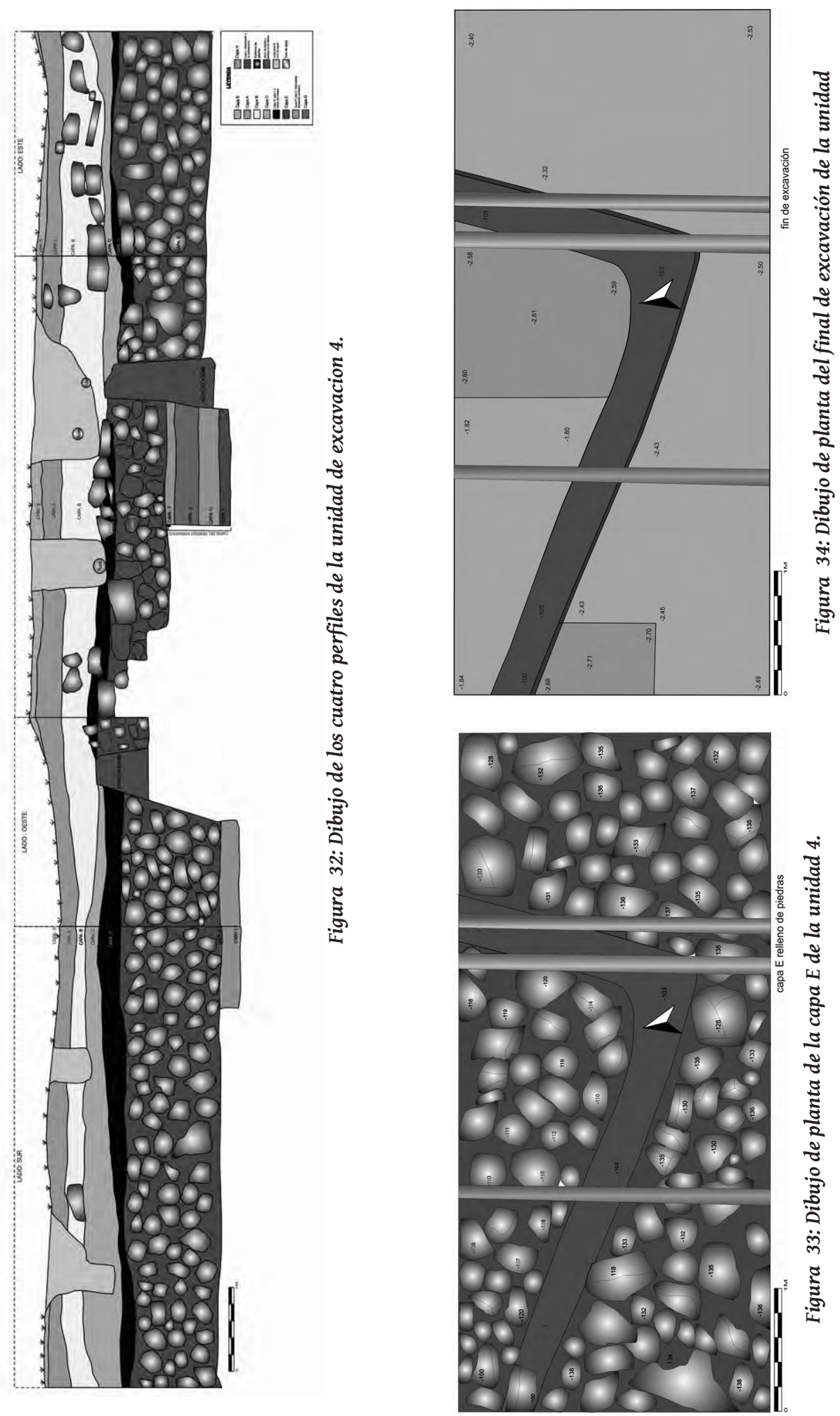


\section{CARACTERÍSTICAS DE LAS EVIDENCIAS ARQUITECTÓNICAS HALLADAS:}

1.- Materiales de Construcción: Los materiales de construcción empleados durante el Periodo Formativo son los adobes de formas semirectangulares y semiesféricos dispuestos en una sola hilera y unidos con mortero de barro. Mientras durante el Periodo Intermedio Temprano se reutiliza las edificaciones de la época precedente y las nuevas construcciones serán edificadas con piedras semicanteadas dispuestas en dos hileras y unidas con mortero de barro.

a) Adobes: Se entiende con este nombre a la masa de barro (tierra, arcilla, paja y agua) modelada en formas variadas secados al aire libre y al sol. Las formas y dimensiones varían en el tiempo; para el caso específico de Churucana hemos identificado que las formas de los adobes empleados en la edificación de los recintos arquitectónicos son los semirectangulares de dimensiones variadas, algunos poseen $30 \mathrm{~cm}$ de largo x $20 \mathrm{~cm}$ de ancho, otros $40 \mathrm{~cm}$ de largo x $30 \mathrm{~cm}$ de ancho y su altura también varía de $15 \mathrm{~cm}$ a $20 \mathrm{~cm}$, la coloración que presentan son gris oscuro y marrón. Estos fueron asentados con una capa de mortero de barro, los paramentos de los muros presentan una capa de enlucido de barro y en algunos casos se aplicó una capa de pintura sobre ellos (Figuras 35 y 36).

B) Piedra: Otro tipo de material de construcción empleado es la piedra natural, piedra semicanteada y canteada. Estos fueron utilizados de dos maneras: primero como material de relleno para el sellado ritual de los recintos arquitectónicos. La segunda forma empleada es como material de construcción de muros durante el Periodo Huarpa y Wari.

c) Relleno: Estos se caracterizan por el empleo de diversos tipos de materiales, entre ellos destacan los fragmentos de adobes, fragmentos de rocas calizas, piedras de tamaños variados y tierra. La utilización del relleno en los diferentes momentos de ocupación de la parte media y alta del sitio están relacionados no solamente para el sellado de los recintos arquitectónicos, sino también es probable que se emplearon con la finalidad de nivelar el terreno, otorgar una mayor estabilidad a los pisos y a su vez ganar mayor volumen de las edificaciones que se encuentran en la parte media y alta del sitio (Figuras 37 y 44). En los rellenos también se encuentran materiales culturales variados.
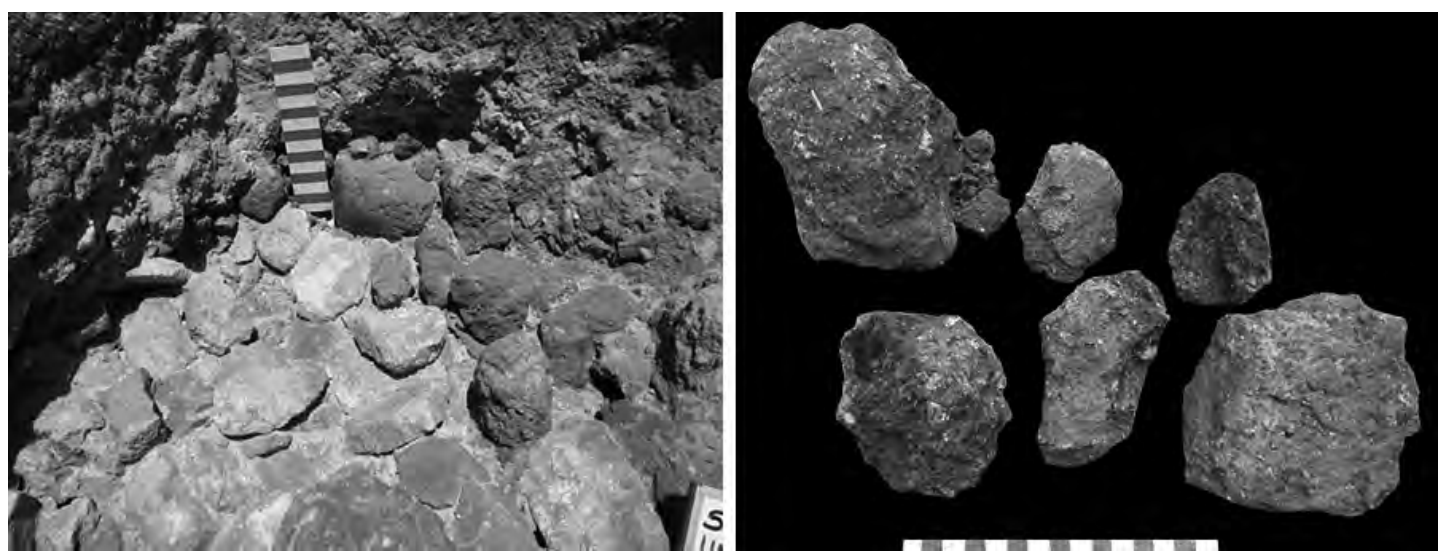

Figuras 37 y 38: Relleno de fragmentos de adobes unidad 2, detalle de los mismos. 
2.- Muros de adobes: En la unidad de excavación Nro 2 (UEA-2) se hallaron dos secciones de muros edificados con adobes y unidos con mortero de barro, estos corresponden a dos estructuras arquitectónicas diferentes y correspondientes a dos momentos de ocupación distintos. En el primer caso se trata del muro 1, el cual presenta una disposición semicircular y por ello se infiere que forma parte de una estructura de forma circular, cuyas dimensiones y demás características lamentablemente no la hemos podemos definir. Sin embargo, hay algunos aspectos que merecen ser tratados: este recinto arquitectónico se encuentra construido directamente sobre el afloramiento rocoso del lugar, el cual previamente fue cavado y acondicionado para dicho fin. Se observa de manera clara la forma circular que adquiere el recinto, observándose nítidamente la forma semirectangular de los adobes, su unión con mortero de barro y su disposición en una sola hilera (figuras 39 y 40). Al interior del espacio formado por este muro se encuentran fragmentos de adobes con huellas de quema, igualmente la cara interna de los adobes que forman parte del recinto presentan claras huellas de actividad de quema, habiéndose hallado restos de ceniza y fragmentos de fibras de molle (Schinus molle). De acuerdo a la secuencia estratigráfica definida, este recinto forma parte de la primera ocupación humana del cerro Churucana ocurrida durante el Periodo Formativo. Luego del cual fue sellada por un relleno para posteriormente edificarse otro muro construido con adobes unidos con mortero de barro (muro 2).
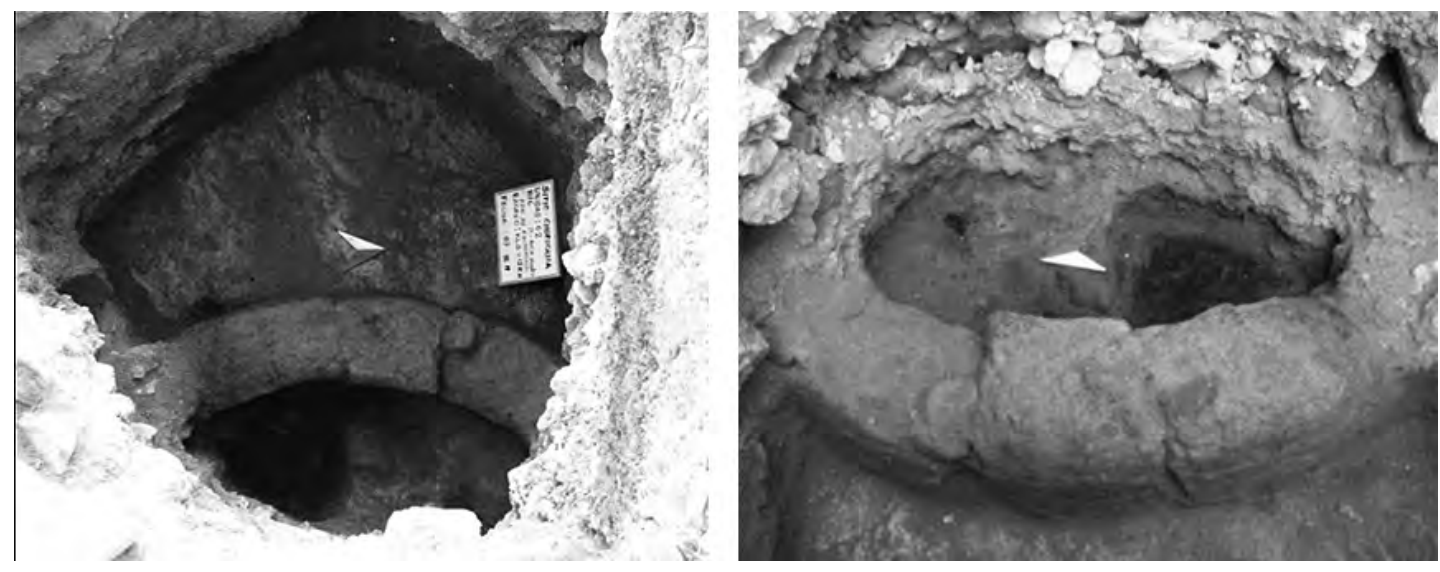

Figura 39 y 40: Disposición semicircular que adquiere el muro 1, construido con adobes de formas semirectangulares y unidos con mortero de barro (Foto: Yuri Cavero).

El muro 2 se desplaza en dirección noroeste-sureste, posee una longitud conocida de $2.20 \mathrm{mts}$ su ancho en la base es $55 \mathrm{~cm}$ y en la parte alta de $33 \mathrm{~cm}$, su altura conservada varia de $0.50 \mathrm{~m}$ a $1.20 \mathrm{~m}$ y fue construido directamente sobre una capa de relleno artificial dispuesta con la finalidad de nivelar el terreno y cubre el recinto formado por el muro 1.

El muro 2 no presenta cimiento y se encuentra asociado al piso 3 que se desplaza en forma horizontal (Figuras 13 y 16). Al igual que el muro 1, ha sido edificado con adobes de formas semirectangulares y unidas con mortero de barro. Presenta enlucido de barro, en el paramento sur se encuentra restos de una finísima capa de pintura, habiéndose identificado la presencia de los colores blanco, amarillo y marrón. Este momento constructivo está también asociado al Periodo Formativo, pues sobre el piso 3 y en el relleno ubicado sobre él se halló fragmentos de cerámica de dicha época. 
Posteriormente este recinto arquitectónico fue sellado con un relleno constituido por fragmentos de adobes, bloques de rocas calizas, piedras y tierra. Este relleno corresponde a un momento de reutilización durante el Periodo Intermedio Temprano (Huarpa) y es en esta época donde se adiciona el piso 2 al muro 2, el cual posteriormente durante el Horizonte Medio nuevamente será sellado con otro relleno que se desplaza sobre el recinto y se adiciona el piso 1 (Figuras 16, 17 y 41).

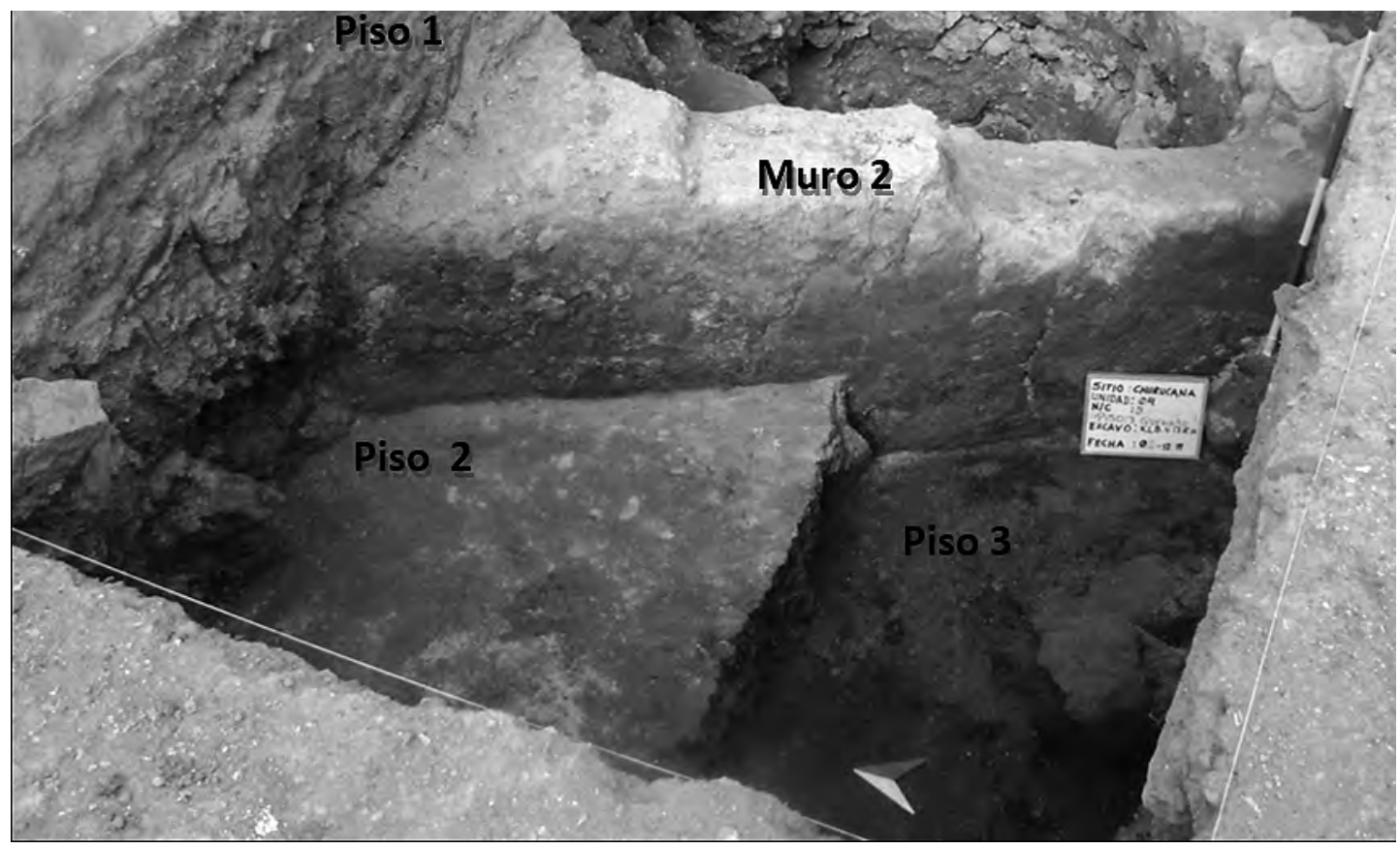

Figura 41: Final de excavación de la unidad 2; obsérvese el muro 2 construido con adobes, presenta enlucido de barro y restos de capas de pinturas. La secuencia de pisos asociados a este muro es la siguiente: piso 1 se desplaza sobre un relleno que cubre el muro 2 y corresponde a la época Wari. Piso 2 vinculado al momento de reutilización del muro 2 ocurrido durante la época Huarpa. El piso 3 es el primer piso asociado directamente al momento de construcción del muro 2, de acuerdo a las evidencias halladas ambos datan del Periodo Formativo.

En la unidad de excavación 4 (UE4) se encontró el Muro 4, este fue edificado con adobes unidos con mortero de barro y presenta enlucido de barro. Este muro corresponde a un segundo momento de ocupación del sitio durante el Periodo Formativo, fue edificado sobre una capa de relleno que está directamente apoyada en el afloramiento rocoso. Se encuentra asociado a un piso de barro y arcilla que se dispone de manera horizontal.

El muro 4 se dispone en forma de una ele (L), la sección más larga se dispone en dirección noroeste-sureste y posee una longitud de $4.15 \mathrm{mts}$ y la sección más corta que se dispone en dirección suroeste-noreste alcanza a tener una longitud de $2.10 \mathrm{mts}$, el ancho es variable, se observa que en la base posee $55 \mathrm{~cm}$ de ancho y en la parte superior $33 \mathrm{~cm}$ y la altura conservada llega a tener $1.50 \mathrm{mts}$.

De acuerdo a las características que presenta se puede inferir que este muro forma parte de un recinto arquitectónico de forma rectangular o cuadrangular de esquinas ligeramente redondeadas tanto al exterior como al interior, con el paramento externo de forma ligeramente inclinada hacia el interior, mientras que en la parte interna el paramento se dispone de forma más lineal (Figuras 42, 43 y 44$)$. 
De otro lado, la forma como ha sido protegido y luego clausurado a modo de un entierro ritual, nos recuerdan tradiciones rituales muy comunes para el periodo formativo y también halladas y descritos en otros sitios de los Andes Centrales. Lamentablemente por el momento las real dimensión, forma y su relación con otras estructuras arquitectónicas similares la desconocemos debido a la escasa dimensión de la unidad de excavación.

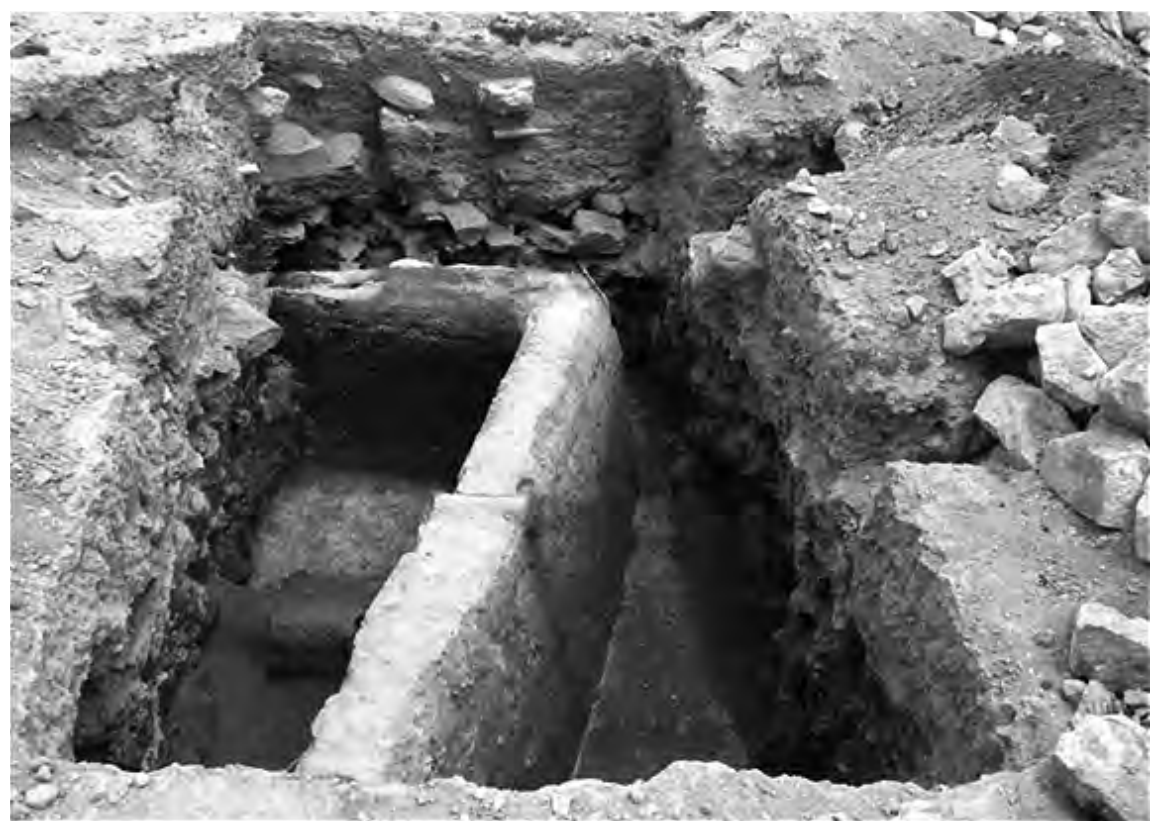

Figura 42: Obsérvese el excelente estado de conservación del muro 4, construido con adobes rectangulares, unidos con mortero de barro, presenta enlucido de barro. Este muro forma parte de un recinto arquitectónico de aparente forma rectangular de esquinas redondeadas. Presenta piso de arcilla y barro hacia la parte exterior e interior del recinto. De acuerdo a la cerámica asociada el recinto es datable al Periodo Formativo y posteriormente fue reenterrado de manera ritual.
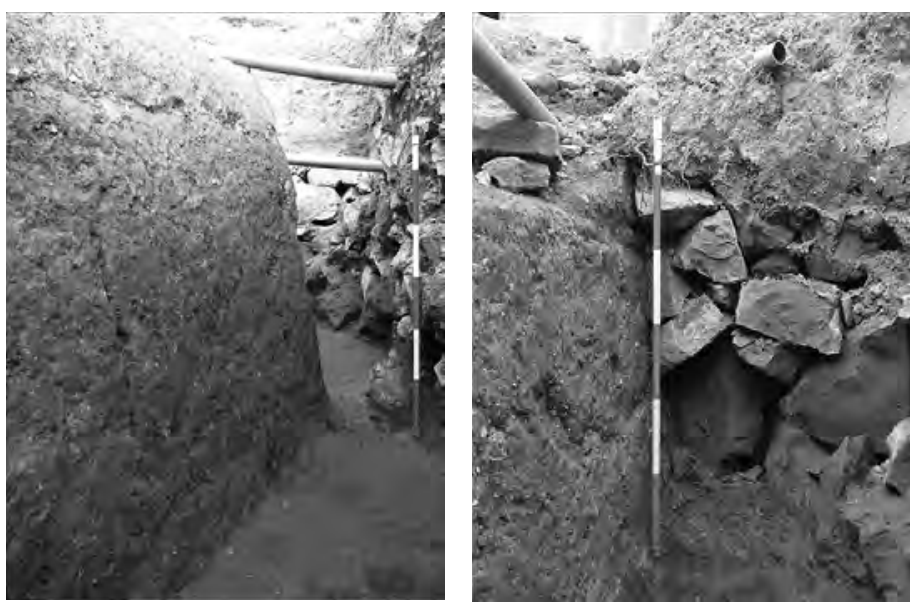

Figuras 43 y 44: Detalle de la parte externa del recinto arquitectónico construido con adobes y enlucido de barro. Al lado derecho obsérvese el relleno de piedras, fragmentos de adobe y tierra dispuestos de manera cuidadosa con la finalidad de reenterrar el recinto arquitectónico. 


\section{3.- Muros de piedra}

En la unidad 1 se halló un muro que se dispone en dirección norte-sur, ha sido construido con piedras alargadas unidas con mortero de barro y dispuestas en dos hiladas, presenta una longitud de $1.35 \mathrm{mts}$, un ancho de $40 \mathrm{~cm}$ y una altura conservada de $20 \mathrm{~cm}$ (Figura 6); los fragmentos de cerámica hallados asociados a estas estructuras arquitectónicas son cerámica Huarpa y Wari.

En la unidad 2 se encontró una base de otro muro de piedras unidos con mortero de barro y orientada de noreste-sureste, fue edificado luego de haberse sellado la estructura arquitectónica construida con adobes. Su longitud total es de $1.55 \mathrm{mts}$, su ancho es de $40 \mathrm{~cm}$ y su altura conservada es únicamente de $12 \mathrm{~cm}$. De acuerdo a la secuencia estratigráfica y por su asociación con fragmentos de cerámica Huarpa, este muro corresponde al Periodo Intermedio Temprano (Figura 15).

En la unidad 3 se hallaron diversas secciones de bases de muros en mal estado de conservación, los cuales probablemente formaban parte de unidades domésticas. Presentan longitudes que proyectadas llegarían a tener entre 3 y 2.50 metros, mientras su ancho varía entre 40 a $50 \mathrm{~cm}$. Estos fueron edificados con cantos rodados y piedras alargadas unidos con mortero de barro. Se encuentran asociadas a tumbas y hoyos de ofrendas ubicados alrededor del mismo en los cuales se hallaron cerámica asociada a la época Huarpa y Wari (Figuras 22 y 24).

4.- Pisos: Los pisos hallados muestran una diferencia constructiva de acuerdo a la época a la que pertenecen. Los pisos del Periodo Formativo estuvieron compuestos básicamente por arcilla y barro, y los pisos relacionados al Periodo Intermedio Temprano han sido construidos con barro y diatomita por lo cual presentan una coloración blanquecina en relación a este último aspecto se tienen similares evidencias en otros sitios de la época Huarpa y Wari, como es el caso de Conchopata y Ñawimpuquio (Leoni 2009; Lumbreras 1975, Ochatoma 2007).

5.- Acabado y Decoración: Con la finalidad de darle un acabado estético a los recintos arquitectónicos, sobre la superficie de los paramentos de los muros de adobes se aplicó una capa de enlucido de barro. Los enlucidos poseen un espesor de 1 a $2 \mathrm{~cm}$ y sobre ellos en algunos sectores aún quedan evidencias de que se aplicó una capa de pintura de color rojo, blanco y amarillo-naranja. Las evidencias halladas durante nuestros trabajos, nos indican que ya desde el Periodo Formativo estos muros presentaban decoración (Figuras 13 y 14).

\section{La CERÁmica Asociada :}

Los resultados preliminares del análisis de cerámica que se vienen efectuando nos dan como resultado la presencia de estilos cerámicos correspondientes a tres momentos históricos: Periodo Formativo, Desarrollos Regionales (Huarpa) y la última a la época Wari.

En las excavaciones que efectuamos se recuperaron un total de 15,787 fragmentos de cerámica, de los cuales 10, 611 son fragmentos no diagnósticos y 5,176 son fragmentos diagnósticos (Figura 45 y Cuadro 1). La mayor parte de los tiestos decorados hallados presentan decoración pintada, siendo mínimos los tiestos con decoración incisa. Los estilos cerámicos a los que corresponden son Wichqana y Bícromo (Periodo Formativo), Kumunsenqa, Caja, Huarpa Tricolor, Huarpa negro sobre blanco, Cruz Pata, Huarpa sobre Ante (Periodo Intermedio Temprano); Chakipampa, Viñaque, Wari Negro (Horizonte Medio), siendo claramente la cerámica del Periodo Intermedio Temprano la de mayor cantidad y predominante en nuestra colección. 


\begin{tabular}{|l|c|c|c|}
\hline & $\begin{array}{c}\text { Fragmentos } \\
\text { Diagnósticos }\end{array}$ & $\begin{array}{c}\text { Fragmentos no } \\
\text { Diagnósticos }\end{array}$ & $\begin{array}{c}\text { Sub } \\
\text { total }\end{array}$ \\
\hline UEA 1 & 3137 & 6421 & 9558 \\
\hline UEA 2 & 723 & 1172 & 1895 \\
\hline UEA 3 & 402 & 1162 & 1564 \\
\hline UEA 4 & 880 & 1724 & 2604 \\
\hline UEA 5 & 34 & 125 & 159 \\
\hline TOTAL & $\mathbf{5 1 7 6}$ & $\mathbf{1 0 , 6 0 4}$ & $\mathbf{1 5 , 7 8 0}$ \\
\hline
\end{tabular}

Figura $N^{\circ} 45:$ Número de fragmentos por unidad y total

De los 15,780 fragmentos de cerámica recuperados, al Periodo Formativo corresponden 442, al Intermedio Temprano 11,774; al Horizonte Medio 208, al Periodo Intermedio Tardío 22 y los fragmentos no definidos son 568 fragmentos (Cuadro $\mathrm{N}^{\circ} 1$ ). Sin embargo, si tomamos en cuenta el comportamiento de la frecuencia de los fragmentos de cerámica recuperados en las unidades de excavaciones 2 y 4 (lugares donde se hallaron los muros de adobes), tendríamos el siguiente comportamiento: de la unidad 2 provienen un total de 1,895 fragmentos, mientras de la unidad 4 provienen 2, 604 lo cual hace un total de 4,499 fragmentos. Si tomamos en cuenta esta última cifra los 442 fragmentos de cerámica del Periodo Formativo representan un $9.82 \%$, lo cual es una cifra muy importante y considerable, debido a que dichos fragmentos provienen de 2 áreas de excavaciones mínimas (calas de $1 \mathrm{~m}$ x $0.50 \mathrm{~m} \mathrm{x}$ $0.25 \mathrm{~m}$ ) a diferencia de los otros grupos de cerámicas correspondientes a los periodos posteriores que provienen de áreas de excavaciones mucho mayores.

\section{La Cerámica del Periodo Formativo}

La cerámica del Periodo Formativo suman 442 y representan el 9.8 \% del total de la cerámica hallada en las unidades de excavaciones 2 y 4 . De la cifra indicada 423 tiestos corresponden al estilo Wichqana y 19 al estilo Bícromo (Figuras 46 al 49). La cerámica Wichqana fue definida por Flores (1960) Lumbreras (1974); Ochatoma (1985,1992) e Isbell (2001). Mientras la cerámica Bícroma en la región de Ayacucho fue documentada por Isbell y otros (1991) para el sitio de Churucana y por Matsumoto y Cavero $(2009,2010)$ para el caso del centro ceremonial de Campanayuq Rumi en Vilcashuamán.

La cerámica Bícroma se caracteriza por la presencia de dos colores rojo y blanco, o también rojo y marrón, los cuales se encuentran delimitados con una línea incisa; el color rojo viene a ser el engobe y se distribuye a modo de una banda en un fragmento de un cuenco, mientras el color marrón viene a ser el color de la pasta; estos tiestos fueron registrados en la capas $\mathrm{G}$ y H, es decir sobre el piso asociado al muro de adobes correspondiente al Periodo Formativo. El nombre de la cerámica Wichqana, deriva del sitio arqueológico de Wichqana investigado por Flores (1960), Lumbreras (1974, 1981) y Ochatoma (1985b, 1992). En nuestros trabajos efectuados en Churucana, la cerámica del estilo Wichqana comprende 442 fragmentos y de acuerdo a la correlación estratigráfica definida viene a ser la alfarería más antigua del sitio arqueológico y se encuentra asociada a la cerámica Bícroma y los muros de adobes que forman parte de diferentes recintos arquitectónicos hallados en las unidades de excavación 2 y 4.

Los tiestos del estilo Wichqana presentan una superficie de color marrón claro con ligeras estrías, poseen una superficie ligeramente brillosa. La pasta se caracteriza por poseer como desgrasante a la 
mica, la cual se encuentra en mayor cantidad que el cuarzo y el feldespato. La técnica de manufactura es el modelado a mano y se observa que la pared de los tiestos no es uniforme y presenta espesores distintos. En los colores son frecuentes los de color marrón claro hasta marrón rojizo y no presentan decoración. La forma de las vasijas son los platos hondos, cuencos, ollas sin cuello, ollas con cuello corto y cántaros de clara función doméstica.

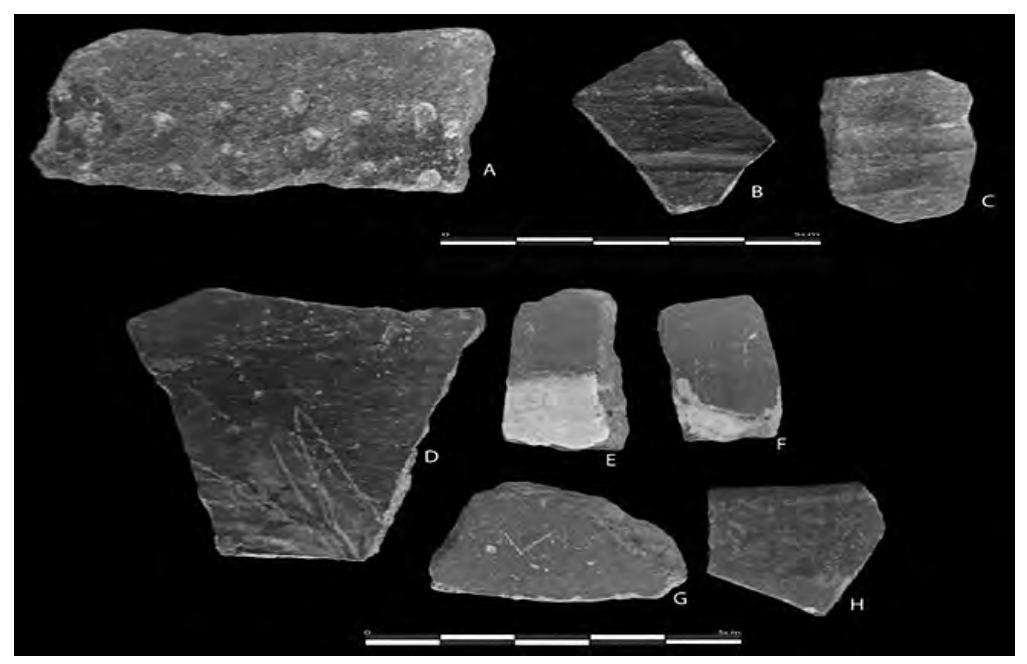

Figura 46: Cerámica formativa asociada al piso 3 y muro de adobes de la UEA- 2
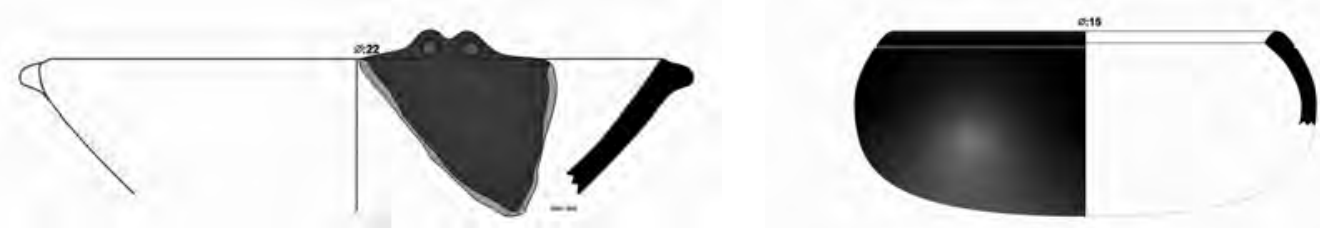

Figura 47: Cerámica formativa hallada en asociacion al muro de adobes y piso de la UEA-4

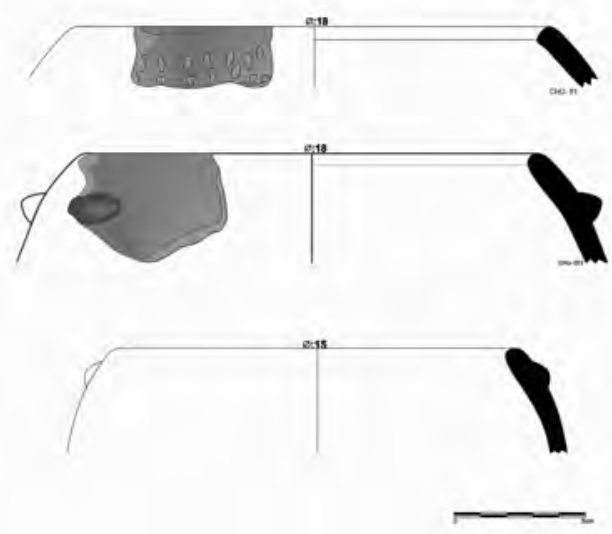

Figura 48: Cerámica formativa con decoracion incisa, punteada y aplicación en forma de botón o apendice. 

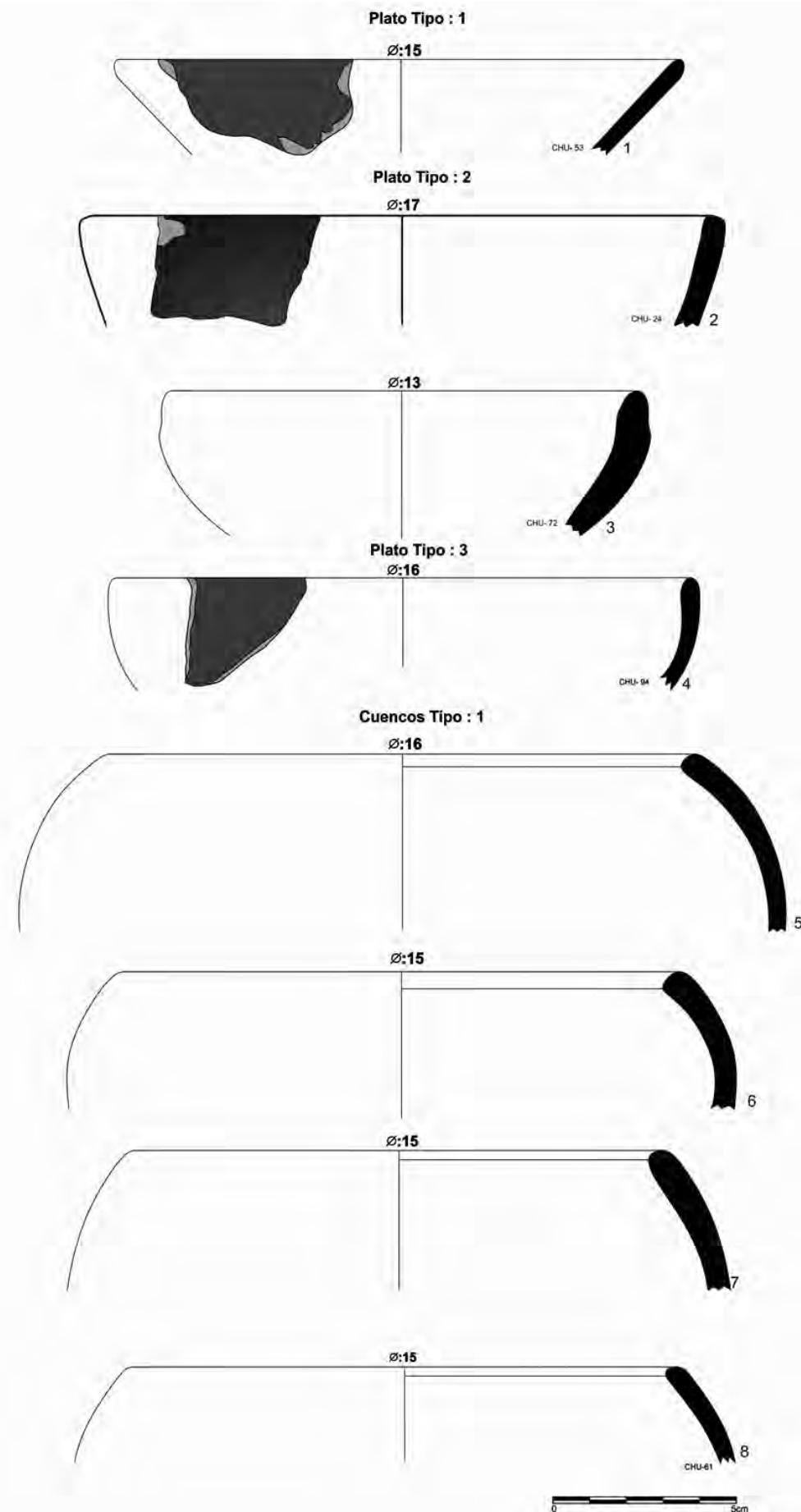

Figura 49. Cerámica del estilo Wichqana: platos de pared divergente y cuencos hemesfericos. 


\section{Cerámica de los Desarrollos Regionales}

El Periodo Intermedio Temprano en Ayacucho se caracteriza por el desarrollo de la cultura Huarpa. Las investigaciones iniciales las efectuaron Duccio Bonavia, Luis Lumbreras y Félix Caycho (1958). Luego siguieron los trabajos de Benavides (1965; 1971; 1983 y 1984), Lumbreras (1974, 2007) Ochatoma y Cabrera (1998). Benavides en las publicaciones referidas sostuvo que la cerámica Huarpa fue más temprana que la cerámica del Horizonte Medio por el hecho que se encuentran en los estratos tempranos de los sitios arqueológicos de Conchopata y Wari.

En Churucana los fragmentos de cerámica correspondientes a este periodo son 11,774 y representan el 74\% del total de la colección recuperada y los estilos cerámicos definidos son: Caja Huamanga, Ocros, Huarpa Negro Sobre Blanco, Huarpa Tricolor, Huarpa Policromo Zig-Zag, Acuchimay y Cruz Pata (Figuras 50 al 53).
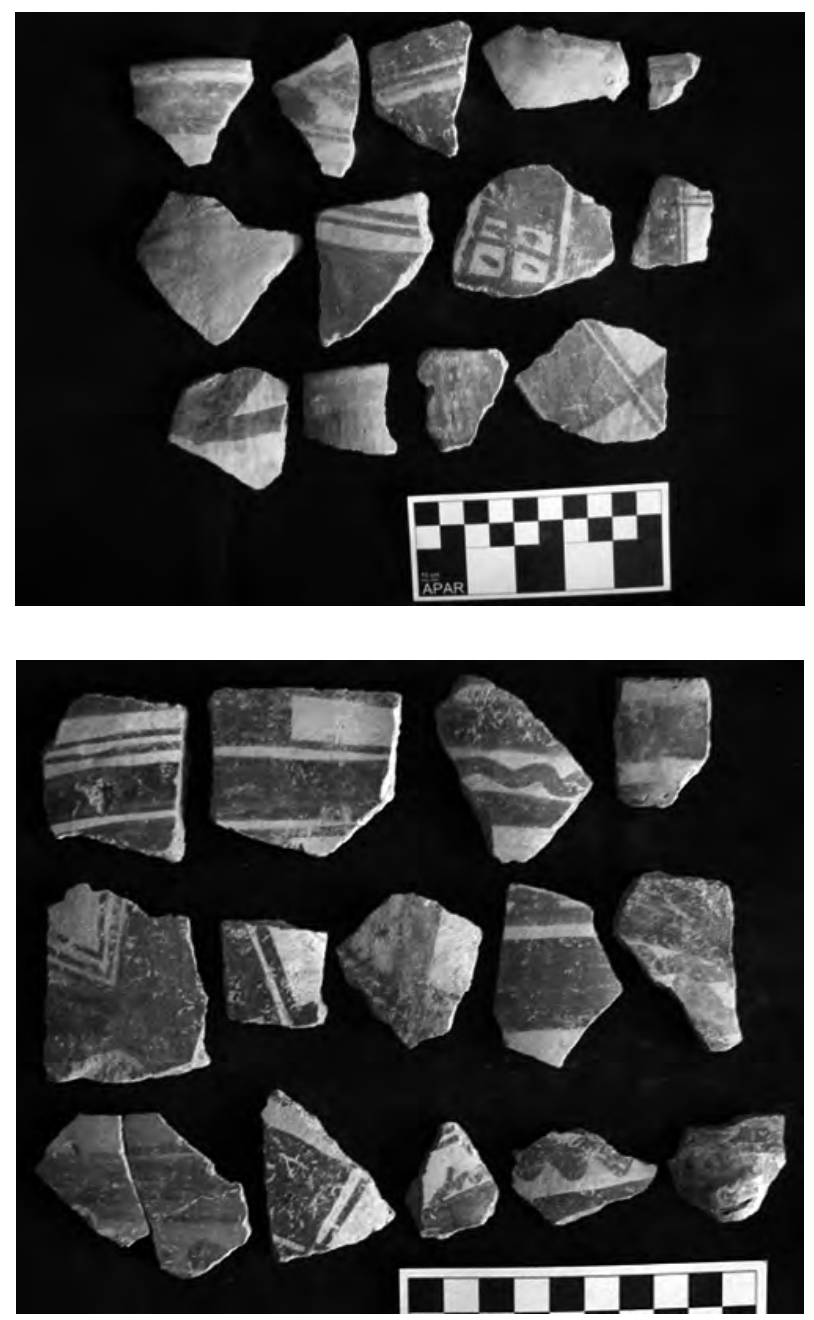

Figuras 50 y 51: Cerámica Huarpa N/B asociados al primer momento de reutilización de los recintos arquitectónicos construidos con muros de adobes del Periodo Formativo. 

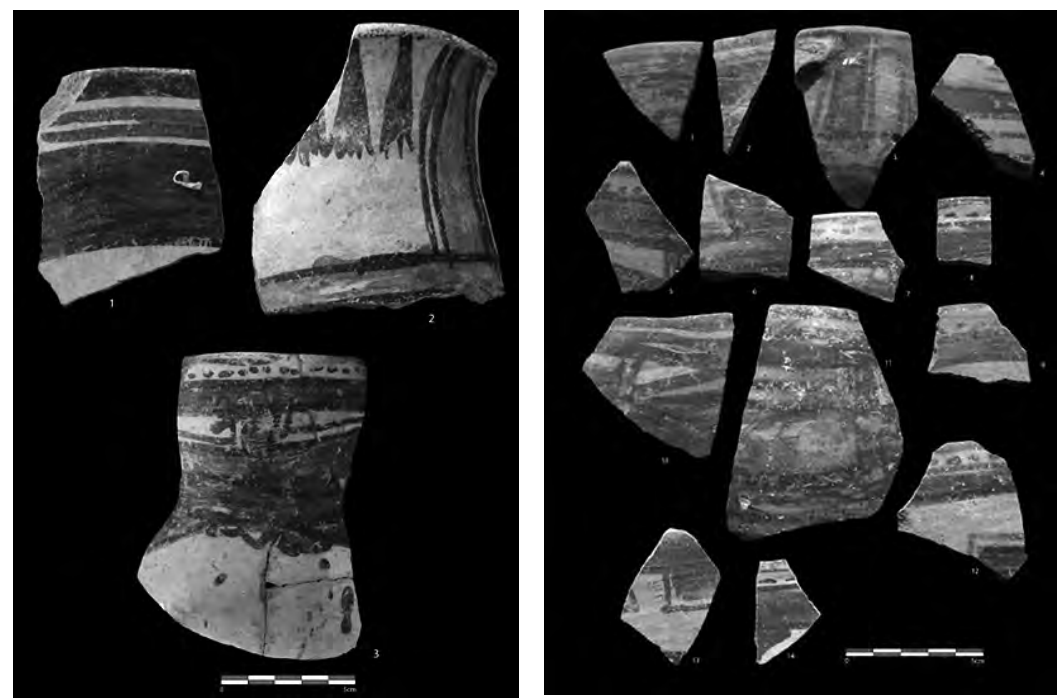

Figuras 52 y 53: Cerámica Huarpa tricolor asociado al segundo momento de reutilización de los recintos construidos con muros de adobes.

\begin{tabular}{|c|c|c|c|c|c|}
\hline \multicolumn{2}{|c|}{ PERIÓDOS } & ESTILOS CERAMICOS & $\begin{array}{c}\text { Frag, } \\
\text { Diagnosticos }\end{array}$ & $\begin{array}{l}\text { Frag, no } \\
\text { Diaguosticos }\end{array}$ & Total \\
\hline \multicolumn{2}{|c|}{ NO DEFINIDO } & - & 166 & 402 & 568 \\
\hline \multicolumn{2}{|c|}{ IMPERIO TAWANTINSUYU } & - & - & - & - \\
\hline \multicolumn{2}{|c|}{$\begin{array}{l}\text { ESTADOS REGIONALES } \\
\text { O INTERMEDIO TARDIO }\end{array}$} & Chanka & 6 & 16 & 22 \\
\hline \multirow{5}{*}{\multicolumn{2}{|c|}{$\begin{array}{c}\text { IMPERIO WARI } \\
\text { O } \\
\text { HORIZONTE MEDIO }\end{array}$}} & Huamanga & 50 & 22 & 72 \\
\hline & & Chakipampa & 21 & 7 & 28 \\
\hline & & Vínaque & 12 & 0 & 12 \\
\hline & & Wari negro & 14 & 11 & 25 \\
\hline & & Oeros & 16 & 55 & 71 \\
\hline \multirow{8}{*}{$\begin{array}{l}\text { DESARROLLOS } \\
\text { REGIONALES } \\
\text { O }\end{array}$} & \multirow{3}{*}{ Fransicional } & Domestico marron & 118 & 1472 & 1590 \\
\hline & & Domestico negor & 108 & 499 & 607 \\
\hline & & Domestico con engobe rojo & 156 & 413 & 569 \\
\hline & \multicolumn{2}{|c|}{ Kumumsenga } & 329 & 946 & 1275 \\
\hline & \multicolumn{2}{|c|}{ Huarpa negro sobre ante } & 398 & 85 & 483 \\
\hline & \multicolumn{2}{|l|}{ Huarpa ante } & 335 & 1102 & 1437 \\
\hline & \multicolumn{2}{|c|}{ Huarpa negro sobre blanco } & 1917 & 3127 & 5044 \\
\hline & \multicolumn{2}{|c|}{ Huarpa trivolor } & 1059 & 2052 & 3111 \\
\hline \multirow{8}{*}{$\begin{array}{l}\text { PERIODO } \\
\text { INTERMEDIO } \\
\text { TEMPRANO }\end{array}$} & \multicolumn{2}{|c|}{ Huarpa tricolor sobre ante } & 52 & 16 & 68 \\
\hline & \multicolumn{2}{|c|}{ Huarpa tricolor sobre naranju } & 63 & 42 & 105 \\
\hline & \multicolumn{2}{|c|}{ Hutarpa policromo } & 20 & 0 & 20 \\
\hline & \multicolumn{2}{|c|}{ Huarpa policroino zigzag } & 25 & 5 & 30 \\
\hline & \multicolumn{2}{|c|}{ Estilo cruz pata } & 18 & 0 & 18 \\
\hline & \multicolumn{2}{|c|}{ Caja } & 10 & 7 & 17 \\
\hline & \multicolumn{2}{|c|}{ Huarpa negro-rojo sobre ante } & 39 & 8 & 47 \\
\hline & \multicolumn{2}{|c|}{ Hutarpa rojo sobre ante } & 109 & 10) & 119 \\
\hline \multirow{2}{*}{\multicolumn{2}{|c|}{$\begin{array}{l}\text { FORMATIVO D } \\
\text { HORIZONTE TEMPRANO } \\
\text { PERIODO INICIAL }\end{array}$}} & Bicromo & 14 & 5 & 19 \\
\hline & & Wichquana & 121 & 302 & 423 \\
\hline \multicolumn{3}{|c|}{ TOTAL } & 5,176 & 10,604 & 15,780 \\
\hline
\end{tabular}

Cuadro $N^{\circ}$ 1: Distribución de fragmentos cerámicos por estilos 


\section{Discusión y CoNCLUSIONES}

A pesar que nuestras unidades de excavaciones fueron mínimas y se efectuaron como parte de un monitoreo arqueologico, la variedad de materiales arqueológicos recuperados, sus respectivas asociaciones y la correlación estratigráfica nos permiten plantear que el sitio arqueológico de Churucana posee una ocupación humana que se inicia a partir del Formativo y llega hasta la época del Imperio Wari.

El primer momento de ocupación está claramente testimoniado por la presencia de muros de adobes semirectangulares y semiesféricos que forman parte de recintos arquitectónicos, asociados a tiestos cerámicos correspondientes a dos tradiciones culturales distintas: el primero de carácter local (Wichqana) y el otro de carácter foráneo (Bicromo) hallados asociados a dichos muros y sus respectivos pisos originales.

La cerámica Wichqana ha sido hallada también en otros sitios arqueológicos de Ayacucho, entre ellos Wichqana (Flores 1960; Lumbreras 1974); Qarqampata de Huamanga (Ochatoma 1985b, 1992), Ira qata (Mancilla 2008), y en menor proporción en Campanayuq Rumi (Matsumoto y Cavero 2009 y 2010). Esta cerámica se caracteriza por presentar una superficie de color marrón claro con ligeras estrías y poseen una superficie ligeramente brillosa pero la superficie de los tiestos no es uniforme y no presentan decoración y las formas predominantes son básicamente de clara función doméstica. Los 442 fragmentos de cerámica Wichqana hallados en Churucana se encuentran asociados a 19 fragmentos de cerámica Bícroma, además de encontrarse estratigráficamente asociados a los pisos más antiguos y a los muros construidos con adobes semirectangulares y semiesféricos hallados en las unidades de excavación 2 y 4.

En relación a la cerámica Bícroma, Isbell y otros (1991) en sus excavaciones llevadas a cabo en el sitio de Churucana también halló 30 fragmentos y sobre ellos escribe lo siguiente:

"El relleno de desechos debajo del piso contenía varios fragmentos incisos y punteados que fueron examinados por Edward Lanning en el verano de 1980. Lanning (comunicación personal) estableció que ellos fueron muy similares a la cerámica de la costa central de Curayacu, después del impacto del estilo Yanamanca. Esto indica un fechado del Horizonte Temprano, sin embargo no especialmente a inicios del Horizonte Temprano, para la edificación. Cinco de los treinta fragmentos recuperados del estrato inmediatamente encima del piso comparte perfiles de bordes con fragmentos debajo del piso, pero los cinco estuvieron decorados con una pintura roja oscura sobre un marrón natural. Esta técnica decorativa quizás se relacione a las tradiciones de cerámica de la sierra sur".

En el centro ceremonial de Campanayuq Rumi ubicado en Vilcashuamán, Matsumoto y Cavero $(2009,2010)$ han reportado el hallazgo de cerámica Bícroma asociados a contextos correspondientes a la fase Campanayuq I. También en Piwrapuquio en la cuenca del rio Mantaro Browman (1970) halló fragmentos de este tipo de cerámica. Sin embargo es en el sitio arqueológico de Ancón ubicado en la costa central donde se encuentran en mayor cantidad este tipo de cerámica (Rosas 2007). Este hecho anteriormente descrito, nos lleva a plantear que a partir de los inicios del Formativo (Periodo Inicial) existían fluidas relaciones entre grupos humanos que vivían en la costa central y en la sierra centro sur de los Andes. Se puede entonces sostener que existían esferas de interacción cultural entre los territorios mencionados y ello implicó el desarrollo de fluidas relaciones sociales entre diversos grupos humanos que se encuentran en estos espacios geográficos, permitiendo de este modo el intercambio de productos variados, técnicas, creencias, afianzamiento de relaciones sociales y quizá también los lazos de parentesco. 
Entonces una de las esferas de interacción cultural durante el Formativo habría incluido a los grupos humanos de las actuales regiones de a Lima, Ica, el valle del Mantaro, Huancavelica y Ayacucho. Es como parte de esta dinámica de relaciones sociales que tenemos que interpretar y entender la presencia de la ceramica Bícroma y de las estructuras arquitectónicas construidas con adobes en Churucana. Por demás esta recordar que la técnica constructiva en base al empleo de adobes no es una tradición típica de la sierra y las evidencias arqueológicas nos indican claramente que se trata de una típica tradición costeña.

Los tipos de adobes con los cuales se edificaron los dos recintos arquitectónicos hallados en las unidades 2 y 4 en Churucana, son los adobes de formas semirectangulares y semiesféricos hechos a mano. No hemos hallado evidencias del empleo de gaberas o moldes para su elaboración, ello explica la diversidad de su longitud, ancho y altura de los adobes. Los adobes semirectangulares y semiesféricos más antiguos han sido documentados en la costa norte y de acuerdo a Reindel (1999), Samaniego (2006), Fuchs y otros (2009) estas formas de adobes han sido hallados conjuntamente con los adobes de formas cónicas y son típicos para la construcción de algunos edificios del Formativo inicial en cerro Sechín, Huaca Lucía, Punkurí, entre otros.

Para el caso de la costa sur, en Ica en el sitio arqueológico de Cerrillos perteneciente a la época Paracas, Splitstoser y otros (2009) refieren que se han hallado estructuras arquitectónicas elaboradas con adobes de forma de pan secados al sol, los cuales han sido asentados con mortero de barro y luego enlucidos con una capa de barro. De igual forma en el sitio arqueológico de Pernil Alto (ubicado en Palpa) Reindel e Isla (2009) reportan el hallazgo de estructuras arquitectónicas de formas rectangulares y cuadrangulares construidos con bloques de barro compacto (adobes?). De otro lado, en Churucana los muros de adobes también forman parte de edificios de formas cuadrangulares o rectangulares que tendrían semejanzas a los descritos por Reindel e Isla para el caso de Pernil Alto. Sin embargo existe una clara diferencia entre ambos sitios, en el caso de Churucana el estado de conservación de los muros de adobes es mejor y ello permitió que en el caso de la UEA4 el muro de adobes tenga una altura conservada de aprox. $1.50 \mathrm{~m}$; asimismo, en el caso del muro hallado en la UEA-2 posee restos de capas de pinturas de colores blanco, marrón y amarillo, lo cual podría sugerir que se trataría de un recinto de función distinta a la doméstica.

Nuestra propuesta de la pertenencia de estas estructuras de adobes al periodo Formativo, se basa en la clara asociación que existe entre los tiestos de cerámica Wichaqana y Bícromo hallados directamente en los pisos más antiguos y en el relleno que se ubica sobre el piso antiguo correspondiente al Formativo. Esta nuestra propuesta encuentra sustento en lo planteado por Isbell y otros (1991), quienes afirman que en el sitio de Churucana hay presencia de arquitectura de adobe y que esta es más temprana al Periodo Huarpa (Intermedio Temprano).

De otro lado la reutilización de estas estructuras arquitectónicas de barro durante la época de los Desarrollos Regionales o Periodo Intermedio Temprano está claramente documentada. En efecto, durante nuestras excavaciones hemos registrado evidencias del cubrimiento de los pisos del Periodo Formativo con un relleno de piedras, fragmentos de adobes y tierra y sobre ellos se acondicionó nuevos pisos también apoyados a los muros de adobes de la época precedente, con la finalidad de reutilizar los ambientes arquitectónicos. En el caso de la unidad 4, se observa que la reutilización implicó una clausura ritual o sellado de la estructura arquitectónica del Formativo.

A los Desarrollos Regionales también corresponde el hallazgo de entierros en cistas en la unidad 3, los cuales están asociados a estilos cerámicos típicos de la época Huarpa: Huarpa Negro sobre Blanco, Huarpa Negro Sobre Ante y Huarpa Tricolor Sobre Naranja, Huarpa policromo, Cruzpata y Ocros. Du- 
rante esta época la región de Ayacucho tuvo mayores contactos con la costa sur, lo cual se ve reflejado también en la cerámica y en la presencia de otros productos exóticos. En relación a la cerámica del Horizonte Medio podríamos decir que su número es mínimo y los tiestos recuperados aparecen en las capas superficiales.

\section{Agradecimientos}

Deseamos agradecer a los arqueólogos Kalia Berrocal, Ronald Sulca, Maribel Gutiérrez, por habernos apoyado en los trabajos de campo. Asimismo a los estudiantes de arqueología de la Universidad Nacional de San Cristóbal de Huamanga: Sonia Laurente, Rudy Huillca, Rosmery López, Henry Navarro, Auria Carina Paullo, por su valioso apoyo prestado durante los trabajos de campo y gabinete.

A los miembros del comité editor de la revista Arqueología y Sociedad por sus valiosas correcciones y sugerencias efectuadas al borrador del presente texto.

\begin{tabular}{|c|c|c|c|c|c|c|c|}
\hline Años & Rowe $(1960)$ & \multicolumn{2}{|c|}{ Lumbreras $(1969-2010)$} & Ayacuelin & Ishell (z001) & \multicolumn{2}{|c|}{$\begin{array}{l}\text { Cerro Churveana } \\
\text { Cavero y Humani } \\
\text { (2015) }\end{array}$} \\
\hline $\begin{array}{l}1532 \\
1476 \\
\end{array}$ & Horizonte Tardio & \multirow{2}{*}{\multicolumn{2}{|c|}{ Imperio del Tawantinsuyo }} & \multirow[t]{2}{*}{ Inca } & \multirow{4}{*}{ RoyacPerja } & & \\
\hline 1440 & \multirow{3}{*}{$\begin{array}{l}\text { Intermedio } \\
\text { Tardio }\end{array}$} & & & & & & \\
\hline 1000 & & \multicolumn{2}{|c|}{ Estados Regionales } & Chanca & & \multirow{2}{*}{\multicolumn{2}{|c|}{ Capa Superficial }} \\
\hline & & \multirow{3}{*}{\multicolumn{2}{|c|}{ Imperio Wari }} & Huari - viftaca & & & \\
\hline \multirow{3}{*}{$\begin{array}{l}6011 \\
5511\end{array}$} & \multirow{3}{*}{ Horizonte Medio } & & & \multirow{2}{*}{$\begin{array}{l}\text { Huari } \\
\text { Huamanga }\end{array}$} & Moraduchayuq & \multirow{3}{*}{\multicolumn{2}{|c|}{$\begin{array}{l}\text { Capa A } \\
\text { Capa B }\end{array}$}} \\
\hline & & & & & \multirow{2}{*}{ Quebrada de Ocros } & & \\
\hline & & \multirow{3}{*}{\multicolumn{2}{|c|}{ Desarrollo Regionales }} & $\begin{array}{l}\text { Huari } \\
\text { Chakipampa }\end{array}$ & & & \\
\hline \multirow{2}{*}{$\begin{array}{l}200 \\
100 \mathrm{dc} \\
0 \\
100 \mathrm{Alc} \\
200\end{array}$} & \multirow[b]{2}{*}{$\begin{array}{l}\text { Intermedio } \\
\text { Temprano }\end{array}$} & & & Нuarps & \multirow[b]{2}{*}{ Fase vista alegre } & \multirow{2}{*}{$\begin{array}{l}\text { Capas } \\
\text { C } \\
\text { D } \\
\text { E. }\end{array}$} & Piso 2 y \\
\hline & & & & \multirow[t]{2}{*}{ Chupas } & & & $\begin{array}{l}\text { Reutilización } \\
\text { de muros de } \\
\text { adobes }\end{array}$ \\
\hline \multirow{3}{*}{$\begin{array}{l}406 \\
700 \\
1000\end{array}$} & \multirow{3}{*}{$\begin{array}{l}\text { IIorizonte } \\
\text { Temprane }\end{array}$} & \multirow{5}{*}{ Fomative } & Formativo & & \multirow{4}{*}{ Fase Churucana } & \multirow[b]{4}{*}{$\begin{array}{l}\mathrm{F} \\
\mathrm{G}\end{array}$} & \multirow[b]{4}{*}{$\begin{array}{l}\text { Muros de } \\
\text { adobes de } \\
\text { estructuras } \\
\text { arquitectónicas }\end{array}$} \\
\hline & & & Superior & \multirow{3}{*}{$\begin{array}{l}\text { Kichkapata } \\
\text { Campanayuq } 2\end{array}$} & & & \\
\hline & & & & & & & \\
\hline \multirow{2}{*}{$\begin{array}{l}1200 \\
1500\end{array}$} & \multirow[t]{2}{*}{ Periodo Inicial } & & Fonnativo Medio & & & & \\
\hline & & & $\begin{array}{l}\text { Formative } \\
\text { Inferior }\end{array}$ & $\begin{array}{l}\text { Campanayuq } 1 \\
\text { Wichgana }\end{array}$ & & $\begin{array}{l}\mathrm{G} \\
\mathrm{H} \\
\mathrm{I}\end{array}$ & $\begin{array}{l}\text { Piso } 3 \text { y muros } \\
\text { de adobes }\end{array}$ \\
\hline \multirow{7}{*}{ 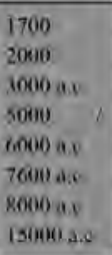 } & \multirow{7}{*}{ Preceranice } & \multirow{3}{*}{\multicolumn{2}{|c|}{ Arcaico }} & Cachi & & & \\
\hline & & & & Chihua & & & \\
\hline & & & & Piki & & & \\
\hline & & & Superior & Jaiwa & & & \\
\hline & & & suption & Puente & & & \\
\hline & & J tive & & Ayacucho & & & \\
\hline & & Litico & Inlenor & Pacaicasa & & & \\
\hline
\end{tabular}

Cuadro $N^{\circ}$ 2: Cuadro cronológico de la región de Ayacucho y ubicación de las evidencias arqueológicas halladas en cerro Churucana. (Elaboración de los autores). 


\section{BiBLIOGRAFÍA}

ALARCÓN GUERRERO, Marlení M.

1990 Olleros de la época Wari. Informe para optar el Grado Académico de Bachiller en Arqueología. Universidad Nacional de San Cristóbal de Huamanga, Ayacucho.

ANDERS, Martha B.

1998 El Estilo Wamanga: resistencia y Subversión simbólica manifestada en la cerámica del Horizonte medio 2. Conchopata: Revista de Arqueología n 1, Pp. 138-162. Universidad Nacional de San Cristóbal de Huamanga, Facultad de Ciencias Sociales. Ayacucho, Perú

BENAVIDES CALLE, Mario.

1965 Estudio de la Cerámica Decorada de Qonchopata. Informe para optar el grado de Bachiller, Universidad Nacional San Cristóbal de Huamanga. Ayacucho.

1971 Análisis de la cerámica Huarpa. Revista del Museo Nacional Tomo XXIII:63-88. Lima

1976 Yacimientos Arqueológicos en Ayacucho. Ayacucho: Universidad Nacional de San Cristóbal de Huamanga.

1983 Análisis de la cerámica Warpa. Ayacucho: Universidad Nacional de San Cristóbal de Huamanga.

1984 Carácter del estado Wari. Ayacucho: Universidad Nacional de San Cristóbal de Huamanga.

BONAVIA, Duccio

1966 Sitios arqueológicos del Perú, primera parte, recopilación y arreglos de Duccio Bonavia. En la revista Arqueológicas $\mathrm{N}^{\circ}$ 9. Publicación del Instituto de investigaciones antropológicas. Museo nacional de antropología y arqueología. Pueblo Libre, Lima, Perú.

CABRERA ROMERO, Martha

1991 Investigaciones Arqueológicas en Waychaypampa. Informe de prácticas pre-profesionales. Universidad Nacional de san Cristóbal de Huamanga. Ayacucho.

1998 El Formativo Superior en Ayacucho: Investigaciones en Waychaupampa. Conchopata: Revista de Arqueología 1:46-71.

CAVERO CARRASCO, María Alina

1985 Iconografía en la cerámica de Qonchopata. Trabajo de investigación presentado para optar el Grado de Bachiller en Ciencias Sociales. Universidad Nacional San Cristóbal de Huamanga. Ayacucho.

1990 Qonchopata: Iconográfica, Mitológica y Ritual. Tesis para optar el Título de Antropóloga: Universidad Nacional San Cristóbal de Huamanga. Ayacucho.

FUCHS, Peter y otros

2009 Del arcaico Tardío al Formativo Temprano: Las investigaciones en Sechín Bajo, Valle de Casma. EN: El Periodo Formativo: Enfoques y evidencias recientes. Cincuenta años de la Misión Arqueológica Japonesa y su vigencia. Boletín PUCP Nro 13 PP. 55-86. Lima Perú. 


\section{KNOBLOCH, Patricia.}

1976 A Study of the Huarpa Ceramic Style of the Andean Early Intermediate Period. Thesis. State University of New York at Binghamton.

1983 A Study of the Andean Huari Ceramics from the Early Intermediate Period to the Middle Horizon Epoch 1. PhD Dissertation. State University of New York at Binghamton.

1988 Artisans of the Realm: Art of the Wari Empire and its Contemporaries. In Ancient Art of the Andean World , S. Masuda and I. Shimada (eds.), pp. 107-123. Tokyo: Iwanami Shoten.

1991 Stylistic Date of Ceramics from the Huari Centers. In Huari Administartive Structure: Prehistoric Monumental Architecture and State Government, W.H. Isbell and G.F. McEwan (eds.), pp. 247-258, Washington D.C.: Dumbarton Oaks.

GONZÁLEZ CARRÉ, Enrique

1981 La Antigua Ciudad de Wari en Ayacucho. Boletín de Lima 16-17-18:83-97.

2007 Historia prehispánica de Ayacucho. Ayacucho: Universidad Nacional de San Cristóbal de Huamanga. Tercera edición González Carré, Enrique y Bragayrac Dávila, Enrique

1986 El templo mayor de Wari, Ayacucho. Boletín de Lima 8(47):9-20.

HUAMANÍ DÍAZ, Jhon René

2012 Análisis del material cultural de la unidad T1 y T2 de Campanayuq Rumi, Vilcashuamán-Ayacucho. Informe practicas Pre-profesionales. Facultad de ciencias sociales. UNSCH. Ayacucho.

ISBELL, William $\mathrm{H}$.

1985 El Orígen del Estado en el Valle de Ayacucho. Revista Andina 3(1): 57-106.

1987 Conchopata: Ideological Innovator in Middle Horizon 1A. Nawpa Pacha 22-23:91- 126.

2001a Repensando el Horizonte Medio: el caso de Conchopata, Ayacucho, Perú. Boletín de Arqueología PCUP 4:9-69.

2001b Huari: crecimiento y desarrollo de la capital imperial. Wari: Arte Precolombino Peruano, pp. 99-172. fundación El Monte, Sevilla.

ISBELL, William H, Gordon f. Mcewan

1991 Una historia de los Estudios Huari y la introducción a las interpretaciones actuales: Estructura administrativa huari prehistórica arquitectura monumental y gobierno estatal, William Isbell y Gordon f. McEwan, Editores, Colección y Biblioteca de Investigación del Dumbarton Oaks Washington, D.C. pag. 1-18

ISBELL, William H., Christine Brewster-Wray, Lynda e. Spickard

1991 Arquitectura y la Organización espacial en Huari: Estructura administrativa huari prehistórica arquitectura monumental y gobierno estatal, William Isbell y Gordon f. McEwan, Editores, Colección y Biblioteca de Investigación del Dumbarton Oaks Washington, D.C. pag.19-58 


\section{KNOBLOCH, Patricia.}

1976 A Study of the Huarpa Ceramic Style of the Andean Early Intermediate Period. Thesis. State University of New York at Binghamton

1983 A Study of the Andean Huari Ceramics from the Early Intermediate Period to the Middle Horizon Epoch 1. PhD Dissertation. State University of New York at Binghamton.

1990 Stylistc Date Of Ceramics From The Huari Centers: Stanfor University.

2000 Crónica del contacto y encuentro cercanos de Wari. Boletín de Arqueología PUCP, $\mathrm{N}^{\circ} 4$. Lima

LUMBRERAS, Luis G.

1960 La Cultura de Wari, Revista de Etnología y Arqueología N¹:130-227, instituto de Etnología y Arqueología, universidad nacional mayor de san marcos, lima, Perú.

1974a Las Fundaciones de Huamanga. Hacia una Prehistoria de Ayacucho. Lima: Editorial Nueva Educación.

2007 El imperio Wari, editorial Altazor, lima

MAC NEISH, Richard; Angel GARCIA COOK; Luis G. LUMBRERAS; Robert K. VIERRA y Antoinette NELKEN-TEMER

1981 Prehistoria de la Cuenca de Ayacucho, Perú volumen II Excavaciones y Cronología. Ann Arbor. Imprenta de la Universidad de Michigan.

1983 Prehistoria de la Cuenca de Ayacucho, Perú volumen IV Excavaciones y Cronología. Ann Arbor. Imprenta de la Universidad de Michigan.

MATSUMOTO, Yuichi; Yuri Igor, CAVERO PALOMINO

2009 Investigaciones Arqueológicas en Campanayuq Rumi, Vilcashuamán-Ayacucho. En la Revista Pacha Runa № 1. Publicación del Instituto de Investigaciones Históricas, Arqueológicas y Antropológicas "Pacha Runa"-IDHAPAR. Editor Edison Mendoza. Pp 25-45. AyacuchoPerú.

2010 Una Aproximación Cronológica del Centro Ceremonial de Campanayuq Rumi, Ayacucho. En Boletín de Arqueología PUCP, No 13(2008) Tomo II pp.323-346. Lima-Perú.

Prensa Rite and fall of the late Initial Period/Early Horizon Center of Campanayuq Rumi in Ayacucho, Peru. En prensa.

MENZEL, Dorothy

1964 Style and time in the Middle Horizon. Ñawpa Pacha 2:1-105.

1968a New Data on Middle Horizon Epoch 2A. Ñawpa Pacha 6:47-114.

1968b la cultura Wari. Las grandes civilizaciones del antiguo Perú. Tomo VI, compañía de seguros, y reaseguros peruano Suiza, Lima.

OCHATOMA PARAVICINO, José

1985a Jargampata de Huamanga: investigaciones arqueológicas en un yacimiento del Horizonte Temprano. Tesis para optar el grado de bachiller. Universidad Nacional San Cristóbal de Huamanga. Ayacucho 
1985b Acerca del Formativo en la sierra centro-Sur. Tesis de licenciatura. Universidad Nacional San Cristóbal de Huamanga. Ayacucho

1989 Aqowayqo, poblado Rural de la Época Wari, CONCITEC. Lima .

1998 El Período Formativo en Ayacucho: balances y perspectivas. In Boletín de Arqueología PCUP 2:289- 302.

2000 Arquitectura y áreas de actividad en Conchopata. Boletín de arqueología PUCP. Lima

2007 Alfareros del Imperio Huari: vida cotidiana y áreas de actividad en

Conchopata. Universidad Nacional San Cristóbal de Huamanga. Lima

2010 Los Huarpas: Caracterización y Tipología cerámica. Área de Investigación Arqueológica. Universidad Nacional San Cristóbal de Huamanga. Ayacucho

OCHATOMA PARAVICINO, José y Martha CABRERA ROMERO.

1997. El modo de vida en un poblado rural H uari. Ayacucho: Universidad Nacional San Cristóbal de Huamanga.

PAULSEN, Allison

1983 Huaca Del Loro revisited: the Nasca-Huarpa connection. In Investigations of the Andean Past. D. Sandweiss (ed.), pp. 98-121. Ithaca: Cornell Latin American Studies Program.

PÉREZ CALDERÓN, Ismael

1998 Excavación y definición de un taller de alfareros Huari en Conchopata. Conchopata: Revista de Arqueología 1:93-137. Universidad Nacional San Cristóbal de Huamanga. Ayacucho

1999 Huari, misteriosa ciudad de piedra. Universidad Nacional San Cristóbal de Huamanga. Ayacucho

2000 Estructuras megalíticas funerarias en el complejo Huari. Boletín PUCP 4:505-547. Pérez Calderón, Ismael and José Ochatoma Paravicino

2004 Arqueología: indicadores de actividades alfareras en Muyu Orgo, Ayacucho. Investigaciones en Ciencias Sociales, Ayacucho: Universidad Nacional San Cristóbal de Huamanga. Pp. 47- 74

PULGAR VIDAL, Javier

1972 Geografía del Perú. Las ocho regiones naturales del Perú. Lima: Editorial Universo S.A.

ROSAS LA NOIRE, Hermilio

2007 La Secuencia cultural del Periodo Formativo en Ancon. Auqui Ediciones. Lima, Perú.

REINDEL, Markus

1999 Montañas en el desierto: la arquitectura monumental de la costa norte del Peru como reflejo de los cambios sociales de las civilizaciones prehispánicas. Socciete suisse des Americanistes. Bul. Nro 63. Pág. 137-148. 


\section{REINDEL, Markus y J. ISLA}

2009 El periodo inicial en Pernil Alto, Palpa, Costa sur del Perú. EN: El Periodo Formativo: Enfoques y evidencias recientes. Cincuenta años de la Misión Arqueológica Japonesa y su vigencia. Boletín PUCP Nro 13 PP. 259-288. Lima Perú.

SAMANIEGO, Lorenzo

2006 Punkurí. Proyecto Cultural. Península Nro 8. Edición Especial. Nuevo Chimbote

SHADY SOLÍs, Ruth

1988 La época Huari como interacción de las sociedades Regionales. Revista Andina 6(1):67-99. Cuzco

SPLITSTOSER, Jeffrey y otros.

2009 Nuevas evidencias de textiles y cerámica de la época Paracas Temprano en Cerrillos, valle de Ica, Perú. EN: El Periodo Formativo: Enfoques y evidencias recientes. Cincuenta años de la Misión Arqueológica Japonesa y su vigencia. Boletín PUCP Nro 13 PP. 259-288. Lima Perú.

TOSI, Joseph

1960 Zonas de vida natural en el Perú. Boletín Técnico N 5. Instituto Interamericano de Ciencias Agrarias, Zona Andina, Lima.

VALDEZ, Lidio

2004 Huarpa, la cultura local del valle de Ayacucho. Revista arqueológica N 7 Huanta.

VALDEZ, Lidio; Julio VALDEZ; Katrina BETTCHER and Cirilo VIVANCO

2000. Marayniyoq, un establecimiento Wari en el valle de Ayacucho, Perú. Boletín PUCP 4:549564).

VALDEZ, Julio Ernesto

2003 Sitios arqueológicos Wari en el valle de Huanta, Ayacucho. Revista Arqueológica Warpa $\mathrm{N}^{\circ}$ 5 pp3.25. Huanta. 